\author{
SANDIA REPORT \\ SAND2010-4800 \\ Unlimited Release \\ Printed September 2010
}

\title{
Test Plan for Validation of the Radiative Transfer Equation
}

Sean Kearney, Thomas K. Blanchat, Allen Ricks, Tom Grasser, and Dann Jernigan

Prepared by

Sandia National Laboratories

Albuquerque, New Mexico 87185 and Livermore, California 94550

Sandia National Laboratories is a multi-program laboratory managed and operated by Sandia Corporation, a wholly owned subsidiary of Lockheed Martin Corporation, for the U.S. Department of Energy's National Nuclear Security Administration under contract DE-AC04-94AL85000.

Approved for public release; further dissemination unlimited. 
Issued by Sandia National Laboratories, operated for the United States Department of Energy by Sandia Corporation.

NOTICE: This report was prepared as an account of work sponsored by an agency of the United States Government. Neither the United States Government, nor any agency thereof, nor any of their employees, nor any of their contractors, subcontractors, or their employees, make any warranty, express or implied, or assume any legal liability or responsibility for the accuracy, completeness, or usefulness of any information, apparatus, product, or process disclosed, or represent that its use would not infringe privately owned rights. Reference herein to any specific commercial product, process, or service by trade name, trademark, manufacturer, or otherwise, does not necessarily constitute or imply its endorsement, recommendation, or favoring by the United States Government, any agency thereof, or any of their contractors or subcontractors. The views and opinions expressed herein do not necessarily state or reflect those of the United States Government, any agency thereof, or any of their contractors.

Printed in the United States of America. This report has been reproduced directly from the best available copy.

Available to DOE and DOE contractors from

U.S. Department of Energy

Office of Scientific and Technical Information

P.O. Box 62

Oak Ridge, TN 37831

Telephone: $\quad$ (865) 576-8401

Facsimile: $\quad$ (865) 576-5728

E-Mail: $\quad$ reports@adonis.osti.gov

Online ordering: http://www.osti.gov/bridge

Available to the public from

U.S. Department of Commerce

National Technical Information Service

5285 Port Royal Rd.

Springfield, VA 22161

Telephone:

(800) 553-6847

Facsimile:

(703) 605-6900

E-Mail:

orders@ntis.fedworld.gov

Online order:

http://www.ntis.gov/help/ordermethods.asp?loc=7-4-0\#online

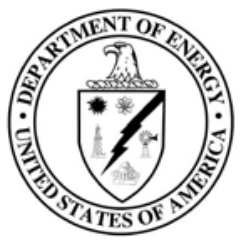


SAND2010-4800

Unlimited Release

Printed September 2010

\title{
Test Plan for Validation of the Radiative Transfer Equation
}

\author{
Sean Kearney, Thomas Blanchat, Allen Ricks, Tom Grasser, and Dann Jernigan \\ Thermal/Fluid Experimental Sciences \\ Fire and Aerosol Sciences Department \\ Sandia National Laboratories \\ PO Box 5800 \\ Albuquerque, NM 87185
}

\begin{abstract}
As the capabilities of numerical simulations increase, decision makers are increasingly relying upon simulations rather than experiments to assess risks across a wide variety of accident scenarios including fires. There are still, however, many aspects of fires that are either not well understood or are difficult to treat from first principles due to the computational expense. For a simulation to be truly predictive and to provide decision makers with information which can be reliably used for risk assessment the remaining physical processes must be studied and suitable models developed for the effects of the physics.

A set of experiments are outlined in this report which will provide soot volume fraction/temperature data and heat flux (intensity) data for the validation of models for the radiative transfer equation. In addition, a complete set of boundary condition measurements will be taken to allow full fire predictions for validation of the entire fire model. The experiments will be performed with a lightly-sooting liquid hydrocarbon fuel fire in the fully turbulent scale range (2 m diameter).
\end{abstract}




\section{CONTENTS}

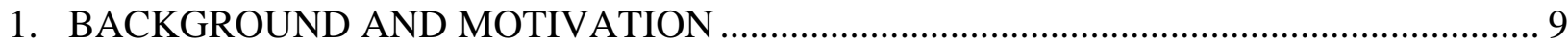

2. Analytical Framework for Experimental Validation of the RTE in Sierra/Thermal-

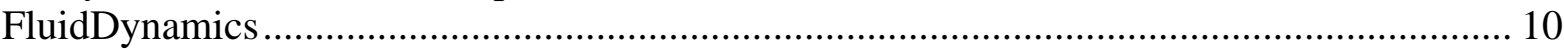

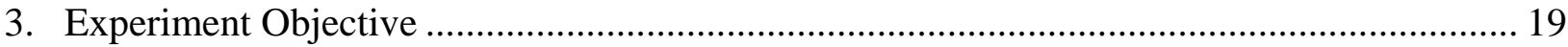

4. Facility, Instrumentation, and Planned Measurements ............................................................ 20

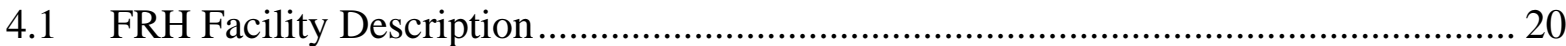

4.2 Principal and Supplemental Measurements ................................................................ 22

4.2.1 Combined CARS/LII Measurements ............................................................ 22

4.2.2 Flame Internal Intensity - Narrow angle radiometers ..................................... 24

4.2.3 Flame Internal Intensity vs Path Length - Spectrometer ................................. 24

4.2.4 Flame Plume Surface Emissive Power ......................................................... 25

4.3 Supplemental and Boundary Condition Measurements.............................................. 25

4.3.1 Total Heat Flux Across the Surface of the Pool -Total Heat

Thermopile Flux Gauges .......................................................................................... 25

4.3.2 Flame topology (Height and Diameter) - Video and IR cameras ................... 27

4.3.3 Fuel Regression Rates.................................................................................... 28

4.3.4 Liquid Level Control and Fuel Temperatures.............................................. 29

4.3.5 Combustion Air Flow Rate and Temperature................................................... 30

4.3.6 Wall Temperatures........................................................................................ 30

4.3.7 Composition of Combustion Products in Overfire Region............................... 31

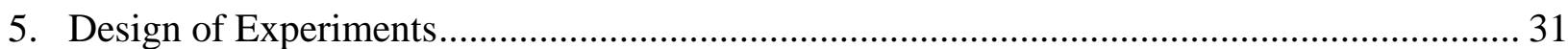

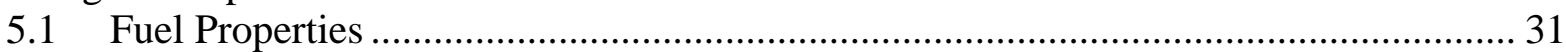

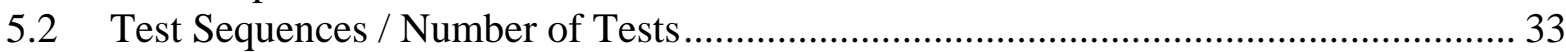

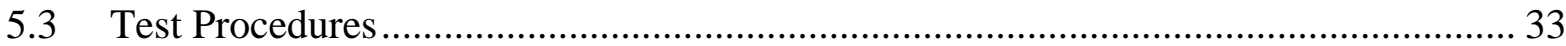

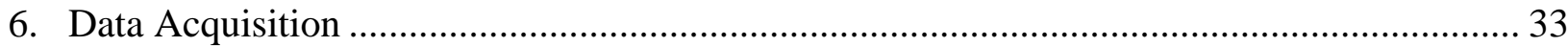

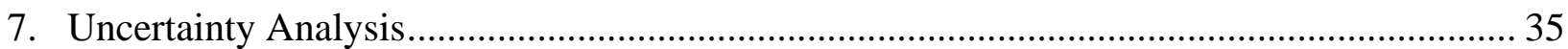

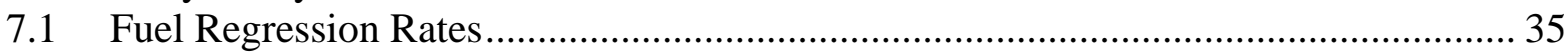

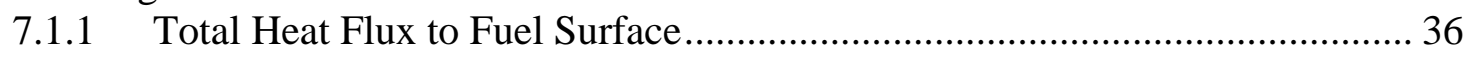

7.1.2 Temperature of Liquid Fuel ......................................................................... 37

7.1.3 Air Flow Rate and Temperature …………………...................................... 38

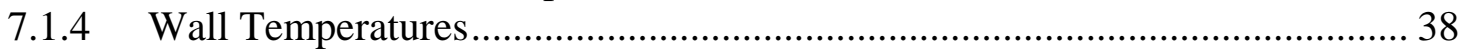

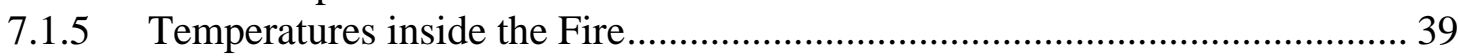

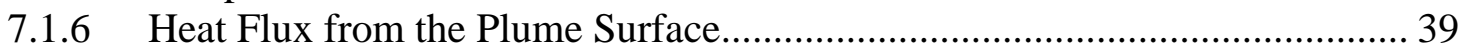

7.1.7 Spectral Transmission Coefficients in Fuel Vapor in Fires............................... 39

7.1.8 Average Flame Height ................................................................................... 40

7.1.9 Combustion Products Composition ................................................................. 40

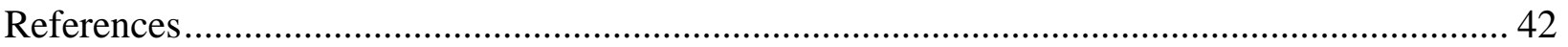

Appendix A: Spatially Resolved Temperature and Soot Measurements Using Laser Diagnostics 


\section{FIGURES}

Figure 1 A cutaway view of the FRH facility showing a pool fire at the ground level, pipes supplying air flow through the basement, the chimney, and instrumentation rooms outside the FRH chamber. .....................................................21

Figure 2 Measured mean velocities at the air ring in the basement of FRH (left) and at the ground level (right).

Figure 3 Positioning system hardware for joint CARS LII measurements in the

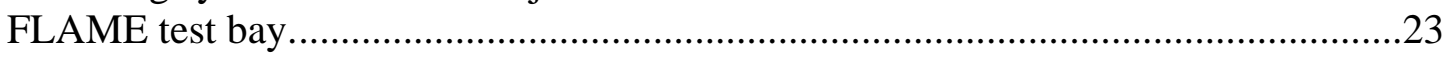

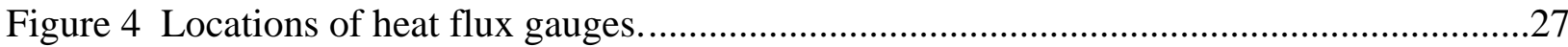

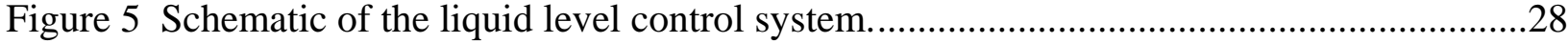

Figure 6 Thermocouple positions in fuel pan. .......................................................................30

\section{TABLES}

Table 1 List of Optical Combustion Diagnostics for RTE Validation Measurements .................18

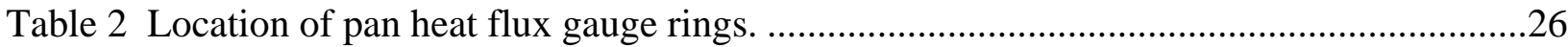

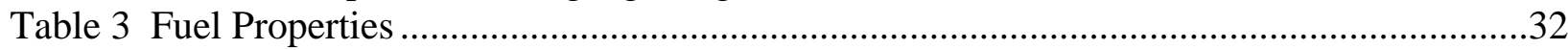




\section{ACKNOWLEDGEMENT}

The authors would like to acknowledge the financial support provided by Campaign 6 for funding this effort (Sheldon Tieszen, Program manager).

The authors also thank Dr. Walt Gill and Dr. Dave Glaze for their thorough peer reviews and excellent comments.

\section{NOMENCLATURE}

CARS coherent anti-Stokes Raman scattering

CGA Combustion Gas Analyzer

DAS data acquisition system

FRH FLAME/Radiant Heat

HP Hewlett-Packard

MUX more multiplexer unit

NI National Instruments

SNL Sandia National Laboratories

TTC Thermal Test Complex 


\section{BACKGROUND AND MOTIVATION}

Radiative emission from even the largest fires is a primarily local phenomenon, occurring at length scales dictated by the size of individual flames within the larger fire plume, and it is prohibitively expensive to resolve in practical fire-simulation models. Moreover, soot volume fraction, unlike many other scalar properties, is not well correlated with the mixture fraction in flamelet-type approaches, rendering soot modeling in turbulent fire environments even more challenging. Further development and refinement of subgrid radiation source-term models, therefore, requires highly spatially and temporally resolved temperature and soot data, as the correlation of these two scalars is needed to describe the generation of soot radiation in large fires.

The equation of radiative transfer (discussed in detail in Section 2) equates the net radiation to an object as the sum of the emitted and absorbed radiation along the line of sight. If we examine the emission term, we see that the local contribution to the radiative flux is given by the product of the soot emissivity, which is proportional to the soot volume fraction, $f_{v}$, and the fourth power of the temperature. The strong nonlinearity resulting from this fourth-power dependence makes the relative position of the soot and temperature distributions at the length scales of individual flames a dominant factor in the prediction of radiative heat-flux generation in large fires. The length scale of the individual flames at which radiative emission is of the order of millimeters, which is well below the grid scale for practical fire simulations.

Experimental investigation of the emission term then requires simultaneous measurement of both $\alpha$ (soot $f_{v}$ ) and $T$ with a temporal resolution that is faster than the turbulent fluctuations and a spatial resolution that is comparable to the flame length scales at which the emission takes place. Laser-based diagnostics offer nanosecond time resolution with spatial resolutions ranging from 10s of microns to a few millimeters. These diagnostics are locally noninvasive, do not suffer from thermal lag and soot buildup that plagues physical probe measurements, such as thermocouples, and can provide multiple parameters simultaneously. We have developed two laser-based approaches for measurement of temperature and soot under a recent LDRD project, and these new 
measurement tools will be exploited for characterization of the radiative emission and absorption terms under C6 funding in FY10. Coherent anti-Stokes Raman scattering (CARS) of the nitrogen molecule will be used for the temperature measurements, with simultaneous laser-induced incandescence (LII) employed for soot-volume fraction determination.

\section{ANALYTICAL FRAMEWORK FOR EXPERIMENTAL VALIDATION OF THE RTE IN SIERRA/THERMAL- FLUIDDYNAMICS}

The goal of this effort is to experimentally validate the form of the radiative transfer equation (RTE) used in Sierra/Thermal-FluidDynamics calculations of pool-fire soot radiation. In particular, we wish to assess the validity of key model assumptions, which include: 1) gray soot radiation and 2) the size of the soot particles is much less than the wavelength of the radiation so that scattering is negligible.

We begin by first incorporating assumption $\# 2$ above, and neglect the scattering terms in the RTE, which then takes the following form,

$$
\frac{d I_{\lambda}}{d s}=\mu_{\lambda} I_{\lambda, b}(T)-\mu_{\lambda} I_{\lambda},
$$

where $I_{\lambda}$ is the radiative intensity at a point, $s$, along the direction of the ray of interest; $I_{\lambda, b}$ is the blackbody spectral intensity at $s$, where the local temperature is $T$; and $\mu_{\lambda}$ is the absorption coefficient. Eq. 1 is valid at any instant in time, for any wavelength, $\lambda$, at any point along any arbitrary path, s. In this context, Eq. 1 simply states that the change in $I$ along $s$ is emission minus absorption. We can integrate Eq. 1 along $s$ to obtain,

$$
\int_{0}^{X} \frac{d I_{\lambda}}{d s} d s=\int_{0}^{X} \mu_{\lambda} I_{\lambda, b}(T) d s-\int_{0}^{X} \mu_{\lambda} I_{\lambda} d s,
$$


and perform the trivial integration on the left-hand side to arrive at

$$
I_{\lambda}(x)-I_{\lambda}(0)=\int_{0}^{x} \mu_{\lambda} I_{\lambda, b}(T) d s-\int_{0}^{x} \mu_{\lambda} I_{\lambda} d s
$$

Here we take the far-field boundary condition at $x=0$ to be cold surroundings at $T=300$ $\mathrm{K}$, where $\tilde{I_{\lambda}}$ is negligible compared to soot radiation at flame temperatures.

The intent of the measurement program is to test the assumptions used in the RTE for soot radiation only, so we will only consider spectral bands $\Lambda=\left[\left(\lambda_{1}, \lambda_{2}\right),\left(\lambda_{3}, \lambda_{4}\right), \ldots\right]$ in which soot radiation dominates gas-band radiation, such as in the 1 to $2 \mu \mathrm{m}$ and/or 3 to 4 $\mu \mathrm{m}$ regions where $\mathrm{CO}_{2}$ and $\mathrm{H}_{2} \mathrm{O}$ are not particularly active. We can then evaluate the terms in Eq. $2 \mathrm{~b}$ directly on a spectrally resolved basis, or integrate over $\Lambda$ to test the assumption of gray soot radiation made in SYRINX radiative-transfer calculations.

\section{Framework for a Band-Integrated Test of the Gray Soot Assumption}

If we integrate over the soot-radiation bands in $\Lambda$, we obtain the following,

$$
I_{\Lambda}(x)=\int_{\Lambda} I_{\lambda}(x) d \lambda=\int_{\Lambda} \int_{0}^{x} \mu_{\lambda} I_{\lambda, b}(T) d s d \lambda-\int_{\Lambda} \int_{0}^{x} \mu_{\lambda} I_{\lambda} d s d \lambda
$$

where $\int_{\Lambda}$ indicates an integration over the chosen spectral band or bands. We now examine the spectral dependence of the absorption coefficient, $\mu_{\lambda}$, to anticipate the consequences of the gray assumption for soot. The spectral absorption coefficient for soot can be found using the Rayleigh-limit expression for soot extinction in the absence of scattering, 
$\mu_{\lambda}=\frac{36 \pi n k}{\left(n^{2}-k^{2}+2\right)^{2}+4 n^{2} k^{2}} \frac{f_{v}}{\lambda}$.

where $f_{v}$ is the local soot volume fraction and $n$ and $k$ are the real and imaginary soot refractive indices. Let us first examine the spectrally-integrated absorption coefficient in the first term on the right-hand side of Eq. 3, which has to do with the local emission. Integrating over the wavelength range, with the blackbody intensity as a weighting function, we obtain,

$$
\mu_{\varepsilon}=\frac{\int_{\Lambda} \mu_{\lambda} I_{\lambda, b}(T) d \lambda}{\int_{\Lambda} I_{\lambda, b}(T) d \lambda} .
$$

It can be shown ${ }^{1}$ that for soot in the small-particle Rayleigh limit the band-integrated absorption coefficient in the emission term takes the form of,

$\mu_{\varepsilon}=f(n, k) f_{v} T \quad$,

where $f$ is a simple function of the real and imaginary soot refractive indices, $n$ and $k$, and the bandwidth of the detected radiation.

If we now examine the spectrally-integrated absorption coefficient for the other term on the right-hand side of Eq, 3, which has to do with the local absorption, we obtain

$$
\mu_{\alpha}=\frac{\int_{\Lambda} \mu_{\lambda} I_{\lambda} d \lambda}{\int_{\Lambda} I_{\lambda} d \lambda},
$$

where the weighting function is now the incident radiation. Calculation of the absorption coefficient for this term therefore requires spectrally-resolved information about the

${ }_{1}^{1}$ M.F. Modest, "Radiative Heat Transfer," McGraw Hill (1993), p. 431. 
incident radiation flux. When only a spectrally-integrated solution is desired, the gray assumption is usually invoked and the absorption coefficient in the second term is set equal to the absorption coefficient in the first term. This is the assumption invoked in Sierra/Thermal-FluidDynamics calculations.

A few observations can be made about Eq. 5 and Eq. 7. If the selected wavelength range is very small, then $\mu_{\lambda}$ will be relatively constant over $\Lambda$ and $\mu_{\varepsilon} \approx \mu_{\alpha}$ regardless of the differences in the distributions of $I_{\lambda}$ and $I_{\lambda, b}(T)$. If $I_{\lambda}$ and $I_{\lambda, b}(T)$ have the same wavelength distribution, then $\mu_{\varepsilon} \approx \mu_{\alpha}$ as well. However, when there are significant differences in the spectral distributions over a large wavelength range, then $\mu_{\varepsilon} \neq \mu_{\alpha}$.

We now make the second key assumption made in the SYRINX calculations (in addition to negligible scattering), which is that the soot radiation is gray. All dependence on $\lambda$ is then removed and the resulting spectrally integrated coefficients for emission and absorption are equal, $\mu_{\varepsilon}=\mu_{\alpha}=\mu$. We further note that,

$$
\int_{\Lambda} I_{\lambda, b}(T) d \lambda=F_{\Lambda}(T) \frac{\sigma}{\pi} T^{4},
$$

where $\sigma$ is the Stefan-Boltzmann constant, and $F_{\Lambda}(T)$ is the fraction of the intensity in the Planck spectrum in the bands considered in $\Lambda$ at temperature $T$, to obtain,

$$
I_{\Lambda}(x)=\frac{\sigma}{\pi} \int_{0}^{x} F_{\Lambda}(T) \mu T^{4} d s-\int_{0}^{x} \mu I_{\Lambda}(s) d s
$$

We can now time average all of the terms in Eq. 9 by the following operations,

$$
\overline{I_{\Lambda}}(x)=\frac{\sigma}{\pi} \frac{1}{\tau} \int_{0}^{\tau} \int_{0}^{x} F_{\Lambda}(T) \mu T^{4} d s d t-\frac{1}{\tau} \int_{0}^{\tau} \int_{0}^{x} \mu I_{\Lambda}(s) d s,
$$


where $\tau$ is a sufficiently long time during the steady state burn for the averages computed from experimental data to converge. Now exchange the order of integration and note that

$$
\begin{aligned}
& 1 / \tau \int_{0}^{\tau} f(x, t)=\bar{f}(x) \text { to get, } \\
& \overline{I_{\Lambda}}(x)=\frac{\sigma}{\pi} \int_{0}^{x} \overline{F_{\Lambda}(T) \mu T^{4}} d s-\int_{0}^{x} \overline{\mu I_{\Lambda}} d s
\end{aligned}
$$

We assume that the correlation, $\overline{\mu I_{\Lambda}}$, between $I$ (a path-integrated quantity) and $\mu$ (a locally determined quantity) is weak, so that $\overline{\mu I_{\Lambda}}=\bar{\mu} \overline{I_{\Lambda}}$. We do not neglect the $\overline{F_{\Lambda}(T) \mu T^{4}}$ correlation. With these assumptions, we arrive at the following expression to formulate a strategy for the planned validation measurements.

$$
\overline{I_{\Lambda}}(x)=\frac{\sigma}{\pi} \int_{0}^{x} \overline{F_{\Lambda}(T) \mu T^{4}} d s-\int_{0}^{x} \bar{\mu} \overline{I_{\Lambda}} d s
$$

Eq. 12 represents an analytical expression to be used as a basis for experiments in which both the assumptions of negligible scattering and gray soot radiation will be tested. To accomplish this, spatial profiles of $\overline{I_{\Lambda}}(x), \bar{\mu}(x)$, and $\overline{F_{\Lambda}(T) \mu T^{4}}$ are required. The diagnostics utilized for each of these measurements are summarized in Table 1 and are discussed in detail elsewhere in this test plan.

It should be noted that while $I_{\Lambda}$ and $T$ are measured directly, the absorption coefficient, $\mu$, must be inferred from LII measurements of soot volume fraction, $f_{v}$. We then must use appropriate model equations to convert $f_{v}$ to $\mu$. We will use expressions of the form of Eq. 6 with a variety of literature values for $n$ and $k$ to estimate graybody soot-absorption coefficients for the evaluation of each term in the energy balance of Eq. 12. 


\section{Framework for a Spectrally Resolved Test of the RTE in the Absence of Scattering}

Since the radiative intensity data inside the fire plume will be spectrally resolved, we can relax the assumption of gray soot behavior and evaluate the RTE using wavelengthspecific quantities. Starting from Eq. 2b, we can perform a similar time-averaging process as in Eq. 10, without performing any spectral integration of the RTE. The resulting wavelength-dependent expression,

$$
\overline{I_{\lambda}}(x)=\int_{0}^{x} \overline{\mu_{\lambda} I_{\lambda, b}(T)} d s-\int_{0}^{x} \overline{\mu_{\lambda}} \overline{I_{\lambda}} d s \quad,
$$

where we have, again, assumed weak correlation between $\mu_{\lambda}$ and $I_{\lambda}$ so that $\overline{\mu_{\lambda} I_{\lambda}}=\overline{\mu_{\lambda}} \overline{I_{\lambda}}$. Eq. 13 can be used for validation of the RTE without the assumption of gray soot radiation. As in the case of Eq. 12, we must relate the LII-measured $f_{v}$ to $\mu_{\lambda}$; this can be accomplished using the Rayleigh-limit expression for soot extinction in the absence of scattering (Eq. 4). Eq. 13 can be spectrally integrated to obtain the equivalent of Eq. 12 without the assumption of gray-soot radiation,

$$
\overline{I_{\Lambda}}(x)=\int_{\Lambda} \int_{0}^{x} \overline{\mu_{\lambda} I_{\lambda, b}(T)} d s d \lambda-\int_{\Lambda} \int_{0}^{x} \overline{\mu_{\lambda}} \overline{I_{\lambda}} d s d \lambda
$$

Comparison of the residuals from Eq. 12 and Eq. 14 provides a partial check of the consistency of the gray soot assumption, especially if the wavelength range is large enough to have a wide variation in the spectral absorption coefficient of soot. If the residuals are smaller for Eq. 14 than for Eq. 12, then the degree of improvement in the residuals is an indication of the consequence of the gray assumption. 


\section{Additional Checks on the Consistency of the Gray Soot Assumption}

Additionally, we can compute $\mu_{\varepsilon}$ and $\mu_{\alpha}$ from their fundamental definitions using experimentally derived information regarding $I_{\lambda}$ and $I_{\lambda, b}(T)$ from the IES and CARS data. The time-averaged absorption coefficient used in the last term on the right-hand side of Eq. 12 is the time-averaged form of Eq. 6,

$$
\overline{\mu_{\varepsilon}}=f(n, k) \overline{f_{v} T}
$$

This absorption coefficient is actually based upon the emission term (the first term on the right-hand side of Eq. 12), and is applied everywhere when the gray assumption is invoked. If the gray assumption is not invoked, the spectrally-integrated and timeaveraged absorption coefficient for the same term can be approximated as

$$
\overline{\mu_{\alpha}}=\frac{\int_{\Lambda} \overline{\mu_{\lambda}} \overline{I_{\lambda}} d \lambda}{\overline{I_{\Lambda}}}
$$

This approximation cannot be justified when time-averaging Eq. 7, but it is useful in the present context because it can be thought of as the absorption coefficient that makes the second term on the right-hand side of Eq. 12 equivalent to the second term on the righthand side of Eq. 14. Using IES measurements of $I_{\lambda}$, CARS temperature measurements for calculation of $I_{\lambda, b}(T)$ and LII-determined soot $f_{v}$ in conjunction with Eq. 4 for calculation of $\mu_{\lambda}, \overline{\mu_{\varepsilon}}$ and $\overline{\mu_{\alpha}}$ can be calculated at selected points along the path. The agreement of $\overline{\mu_{\varepsilon}}$ and $\overline{\mu_{\alpha}}$ to each other can be used as a validation of the gray soot assumption that does not depend upon the results of Eq. 12, and the differences between $\overline{\mu_{\varepsilon}}$ and $\overline{\mu_{\alpha}}$ may help to explain differences in the residuals of Eq. 12 and Eq. 14.

In the preceding discussion it has been assumed that the only spectral bands being considered are bands in which gas-phase species do not contribute significantly. This is 
necessary when validating the solution of the RTE using the residuals of Eqs. 12 through 14, where gas-band contributions cannot be accounted for. The RTE cannot be fully evaluated in bands in which the gases participate strongly, but the energy absorbed and emitted by soot can still be assessed. The energy absorbed and emitted by soot in these bands is relevant to the question of the degree to which soot actually behaves as a gray body in a fire, so this question is best addressed by comparing $\overline{\mu_{\varepsilon}}$ to $\overline{\mu_{\alpha}}$ when integrated over the entire range of the IES measurements.

\section{Summary of Measurement Approaches for RTE Validation}

Each of the three terms in Eqs. 12 and 14 will be determined by sampling $I_{\Lambda}, \mu$, and $T$ in a pointwise fashion for 30-40 minutes. The $I_{\Lambda}$ measurements will be performed using a separate diagnostic than for the $\mu / T$ data, so that these results will not be correlated. The $\mu / T$ data will be recorded simultaneously, and should be statistically correlated for a measurement of the $\overline{\mu T^{4}}$ term in the turbulent pool-fire environment. We anticipate $10^{4}$ statistically independent (not time correlated) samples to be obtained for calculation of the time-mean in Eq. 6. These integrals in Eq. 6 will be numerically evaluated using data from 8-10 $x$ locations along the line of sight. The measurement techniques to be employed are summarized in Table 1; the details of these diagnostic approaches can be found later in this test plan. 
Table 1 List of Optical Combustion Diagnostics for RTE Validation Measurements

\begin{tabular}{|l|l|}
\hline \multicolumn{1}{|c|}{ QUANTITY } & \multicolumn{1}{|c|}{ MEASUREMENT APPROACH } \\
\hline Temperature, $T$ & Coherent anti-Stokes Raman scattering (CARS) \\
\hline Absorption coefficient, $\mu$ & $\begin{array}{l}\text { Laser-induced incandescence (LII) measurements of soot } f_{v} \\
\text { combined with soot refractive index and model to } \\
\text { convert } \boldsymbol{f}_{\mathbf{v}} \underline{\text { to } \boldsymbol{\mu}}\end{array}$ \\
\hline Radiation Intensity, $I_{\Lambda}$ & $\begin{array}{l}\text { Infrared emission spectroscopy (IES) limited to soot- } \\
\text { dominated radiation bands }\end{array}$ \\
\hline Emission term, $\overline{\mu T^{4}}$ & \begin{tabular}{l} 
Simultaneous CARS and LII temperature and soot $f_{v}$ \\
\hline
\end{tabular}
\end{tabular}




\section{EXPERIMENT OBJECTIVE}

Using $2 \mathrm{~m}$ diameter liquid mixtures of methanol and toluene hydrocarbon fires, the objectives of the present experiments are:

1. Map the soot volume fraction and temperature for a variety of sooting fuels

2. Measure flame intensity inside the fire

3. Measure total heat flux (convection and incident radiation) integrated across the surface of the pool

4. Measure flame surface emissive power

5. Measure flame topology (height and diameter)

6. Measure fuel regression rates

7. Measure additional parameters as necessary to allow a complete set of boundary condition data (combustion air flow, fuel and ambient air temperatures, ambient pressure, facility wall temperatures, combustion air products, etc.)

A brief overview describing how these objectives will be achieved is presented in the following paragraphs. The measurement techniques and instrumentation used will be discussed in greater detail in the measurement section.

1. Soot volume fraction and temperature - CARs

2. Flame intensity - Narrow angle radiometers and spectrometers

3. Total heat flux across the surface of the pool - DFTs or thermopiles

4. Flame surface emissive power - Narrow angle radiometers

5. Flame topology (height and diameter) - Video and IR cameras

6. Fuel regression rates - mass loss rate of fuel

7. Additional parameters:

a. Combustion air flow - installed facility flow instrumentation

b. Fuel and ambient air temperatures - TCs

c. Ambient pressure - Pressure transducers

d. Facility wall temperatures - installed facility instrumentation

e. Combustion air products - installed facility instrumentation 


\section{FACILITY, INSTRUMENTATION, AND PLANNED MEASUREMENTS}

\subsection{FRH Facility Description}

The experiments using liquid hydrocarbon fuels will be studied in controlled fire environments in the FLAME/Radiant Heat (FRH) test cell in the Thermal Test Complex (TTC) at Sandia National Laboratories (SNL). The main test chamber of the FRH cell is cylindrical in shape, $60 \mathrm{ft}(18 \mathrm{~m})$ inner diameter with a height around the perimeter of 40 $\mathrm{ft}(12 \mathrm{~m})$. The ceiling slopes upwards $\left(\sim 18^{\circ}\right)$ from the perimeter walls to a height of $48 \mathrm{ft}$ ( $15 \mathrm{~m}$ ) over the center of the facility. A round hole at the top of the facility $16 \mathrm{ft}$ (4.9 m) diameter transitions to a $10 \mathrm{ft}$ by $12 \mathrm{ft}$ ( $3.0 \mathrm{~m}$ by $3.7 \mathrm{~m}$ ) chimney duct (see Figure 1 ). The outer walls are made of steel channel sections and are filled with water that acts as a thermal sink during tests.

The ground level of FRH can be divided into three concentric sections. At the center of the facility is a fuel pan or gas burner. The facility can operate a gas burner $\left(\mathrm{He}, \mathrm{H}_{2}\right.$, $\mathrm{CH}_{4}$, etc.) or a liquid fuel pool (JP-8, methanol, etc.) up to $3 \mathrm{~m}$ in diameter. The test series discussed in this test plan will utilize a $2 \mathrm{~m}$ liquid fuel pool. The second section is a steel spill plate, which extends to a diameter of $6 \mathrm{~m}$. The floor of the outer section is made of a steel grating, through which air is supplied to the FRH chamber during fire experiments. FRH is designed for flexibility in fuel types and a number of different fuels will be used in the present test series to evaluate spectral radiation fluxes to the fuel surface and regression rates for fuels of varying sooting propensities. 


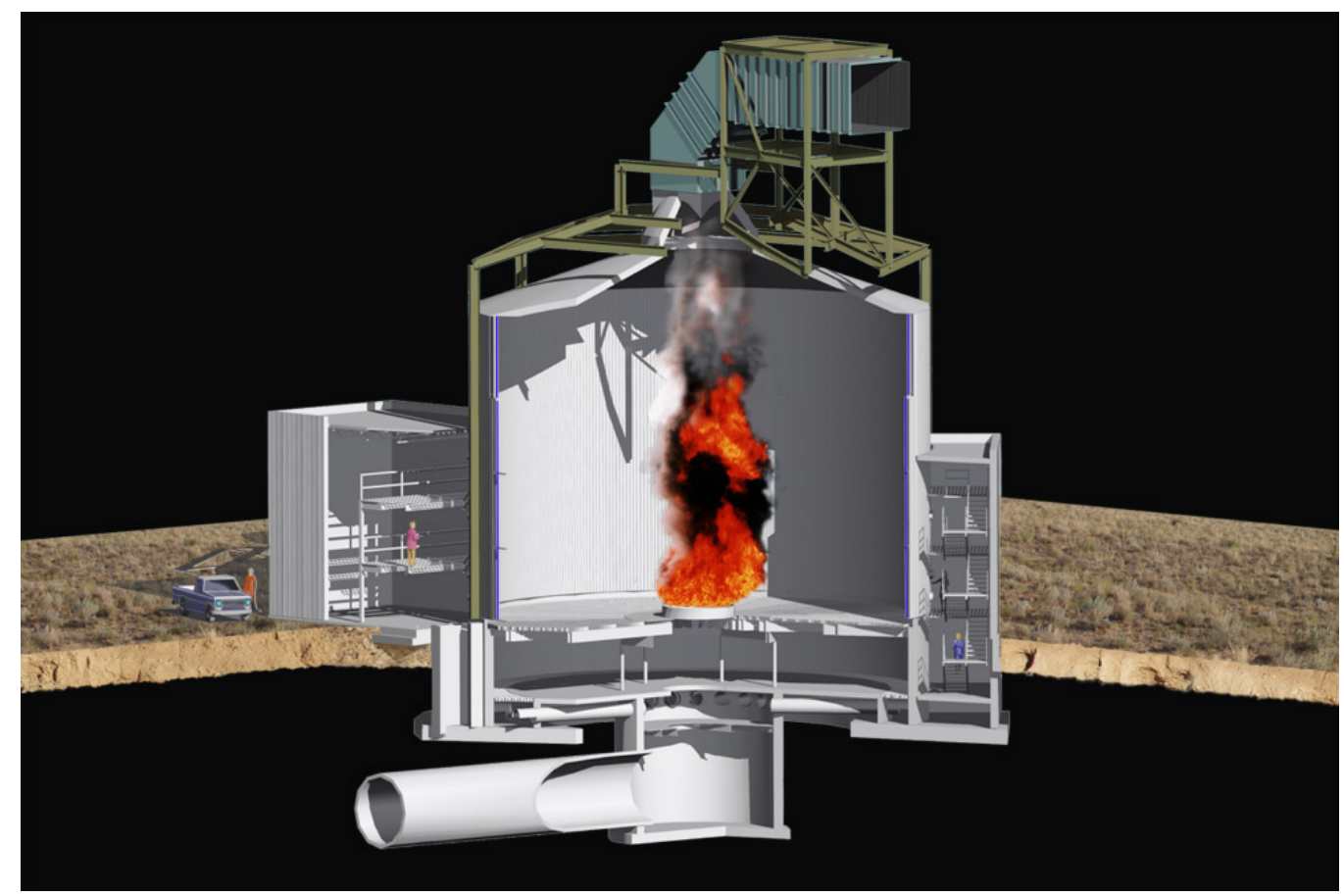

Figure 1 A cutaway view of the FRH facility showing a pool fire at the ground level, pipes supplying air flow through the basement, the chimney, and instrumentation rooms outside the FRH chamber.

The air flow in the FRH chamber combines contributions due to the buoyancy-controlled fire and due to the forced flow of air through the facility. The air flow in the absence of a fire has been characterized experimentally at the air ring in the basement and at the ground level [Ricks, 2006]. The air ring flow field was found to exhibit a pattern (left side of Figure 2) attributable to the 18 supply pipes carrying the air from the diffuser in the center of the facility to the air ring along the outer edges of the facility (refer to Figure 1). The air flow at the ground level was found to be highest in the outer portion of the FRH cell, and exhibited a large recirculation zone in the inner portion of the facility, where mean velocities were in the negative (downward) direction (right side of Figure 2). The presence of a fire at the center of the facility is likely to reduce the recirculation because the air flow will be drawn inwards and entrained into the buoyant fire plume. 

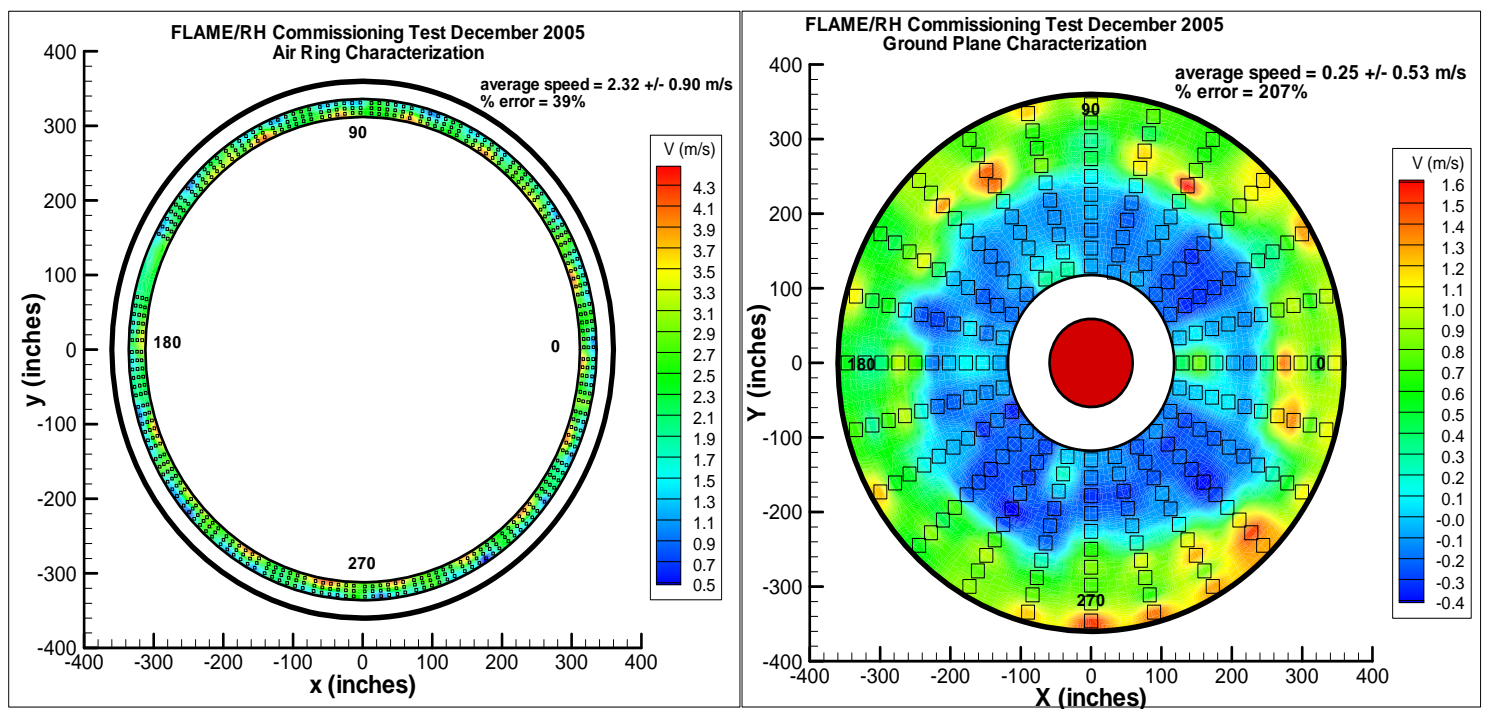

Figure 2 Measured mean velocities at the air ring in the basement of FRH (left) and at the ground level (right).

The test series discussed here will be performed with a liquid level control system to maintain a constant level of liquid fuel in the pan. Changes in the fuel level have been shown by Orloff and de Ris [1982] to influence the shape and burning characteristics of a fire, which they attributed to tripped turbulence at the lip of the pan.

\subsection{Principal and Supplemental Measurements}

\subsubsection{Combined CARS/LII Measurements}

A major objective of C6-funded efforts in 2010 will be the collection of joint CARS/LII data for experimental estimates of the turbulent soot-temperature correlation at flame length scales. Two-meter base diameter fires will be investigated with a blended methanol/toluene liquid fuel for the purposes of obtaining validation-quality data at different vertical positions and along several lines of sight. To accomplish this, capitalequipment-funded positioning stages for both optical hardware and the 2-m-diameter burner will be utilized. A schematic of the positioning system inside the FLAME test bay is provided in Fig. 3. 


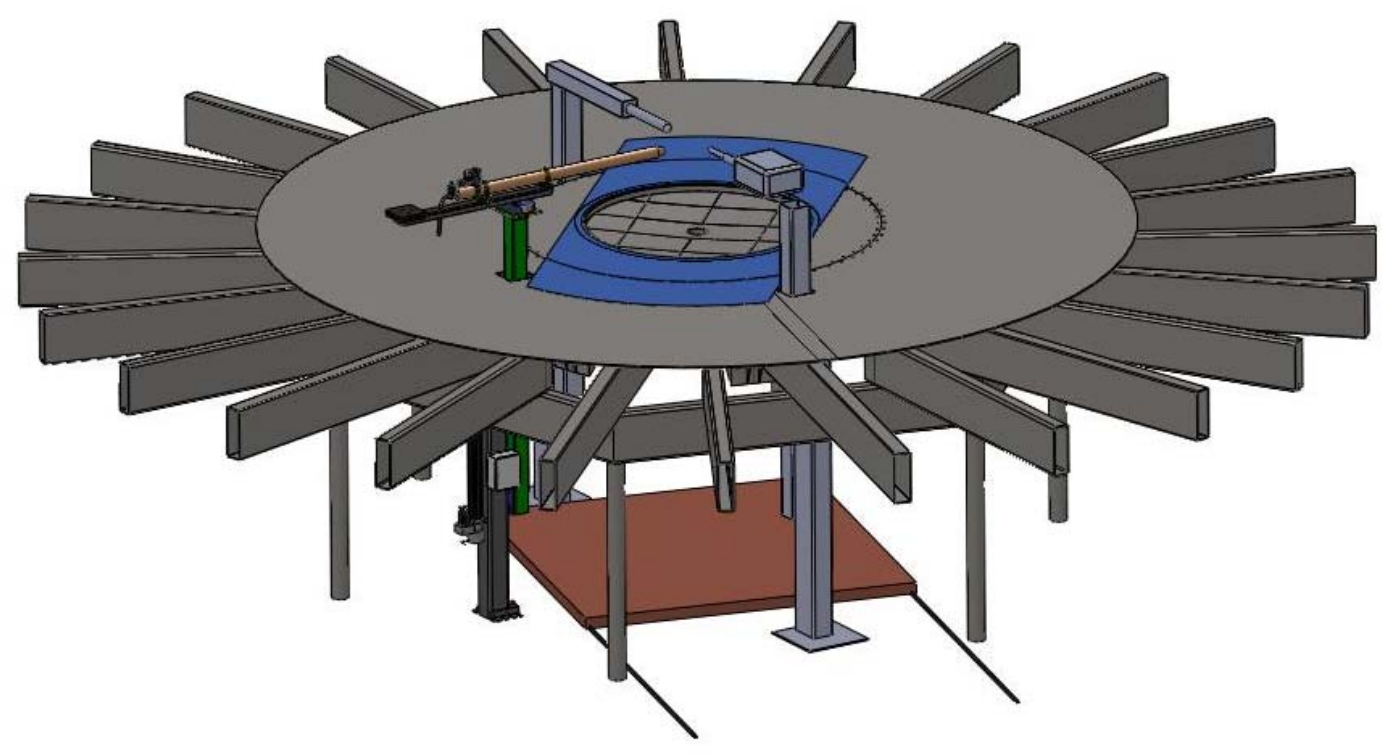

Figure 3 Positioning system hardware for joint CARS LII measurements in the FLAME test bay.

Three separate vertical lifting platforms will be utilized for automated movement and control of the focusing optics for both CARS/LII probes, the CARS signal collection optics, and the water-jacketed LII collection optics (shown in Appendix A Fig. 7). These lifting platforms will provide synchronous lifting of the optical assemblies with submillimeter accuracies with heights ranging from $0.25 \mathrm{~m}$ to more than $2 \mathrm{~m}$ above the fire ground plane. A fourth lifting platform (not shown in Fig. 3) will provide automated translation of the laser beams for CARS/LII probing. Horizontal positioning of the joint CARS/LII measurement volume will be provided by a horizontal positioning system mounted beneath the pan/burner platform at the FLAME basement level (i.e., the pan will translate horizontally $\pm 0.5 \mathrm{~m}$ from centerline). The goal will be to obtain estimated of the joint temperature/soot statistics at 10 different points along lines of sight at several vertical locations, so that the emission term can be estimated at different heights above the burner surface by sampling these experimentally obtained joint pdf data. The results can be used to compute soot-radiation spectra and compare to predications from computational models. 


\subsubsection{Flame Internal Intensity - Narrow angle radiometers}

There is an interest to measure the change in fire intensity as a function of path length. One possible method is to utilize narrow angle $\left(1^{\circ}\right)$ Schmidt-Boelter type water-cooled and gas purged thermopile heat flux gauges (designed for $100 \mathrm{~kW} / \mathrm{m}^{2}$ but calibrated to $193 \mathrm{~kW} / \mathrm{m}^{2}$ ) arranged on a single probe mount to view intensity inside the flame zone at various points and orientations along a horizontal axis. The probe will translated within the fire to allow measurements at the same locations as for the CARS/LII probe. NOTE: These measurements cannot be performed simultaneously with the CARS measurements, as the probe would cause interference.

\subsubsection{Flame Internal Intensity vs Path Length - Spectrometer}

Another possible method to measure the change in fire intensity as a function of path length is to attach a horizontal stainless steel (or other material, possible water-cooled) tube (3-4 inch diameter) to an imaging spectrometer (model ES-200, Spectraline, Inc., West Lafayette, IN) and take mid-infrared spectral radiation intensity measurements. The tube will be translated within the fire to allow measurements at the same locations as for the CARS/LII probe.

The ES-200 measures spectral radiation intensity in the 1.3 to 4.8 micron wavelength range. This wavelength range accounts for $75 \%$ of the emitted radiation energy from a blackbody source at $1420 \mathrm{~K}$, which is approximately the effective radiation temperature from a large hydrocarbon fuel fire as determined by Kearney [2001]. The view angle of the spectrometer is approximately 0.25 degrees. The spectrometer will be mounted outside the fire. A small flow of nitrogen through the spectrometer and pipe will keep the optics clean and eliminate the contaminating effects of changes in gas composition within the pipe. The spectrometer and pipe will be mounted on a positioning system which traverses in the vertical direction to shift the viewing location from a height of $\sim 2 \mathrm{~m}$ above the pool surface to down to the pool surface and in a radial direction from pool centerline to the pool edge. NOTE: These measurements cannot be performed simultaneously with the CARS measurements, as the probe would cause interference. 


\subsubsection{Flame Plume Surface Emissive Power}

Rake-mounted

The surface emissive power radiation from the flame plume will be measured using up to ten (10) narrow angle $\left(1^{\circ}\right)$ Schmidt-Boelter type water-cooled thermopile heat flux gauges (designed for $100 \mathrm{~kW} / \mathrm{m}^{2}$ but calibrated to $193 \mathrm{~kW} / \mathrm{m}^{2}$ ) arranged on a rake to view the plume at various points (both vertically and horizontally).

Wall mounted

Eight narrow-angle radiometers and eight total heat flux gauges will measure the surface emissive power radiation from the flame plume as a function of height. Pairs of gauges, a narrow-angle radiometer (ZnSe window) (Medtherm model NVRW-15-5-360-2183, 50

view angle, range $140 \mathrm{~kW} / \mathrm{m}^{2}$ ) and a total (windowless) heat flux gauge (Medtherm model 64-2-18 with a view angle of $180^{\circ}$, range $15 \mathrm{~kW} / \mathrm{m}^{2}$ ), will be mounted together near the FLAME wall at a distance of $28.64 \mathrm{ft}$. $(8.73 \mathrm{~m})$ from the center of the fire. The spot diameter for the narrow-angle gauges (at $9 \mathrm{~m}$ ) is about $0.8 \mathrm{~m}$. The gauge pairs will be at heights of $\sim 0.5 \mathrm{~m}$ to $4.0 \mathrm{~m}$ with a spacing of $0.5 \mathrm{~m}$ between gauges. The line of sight for each gauge will pass through the centerline of the fire at the height of the gauge. All of the heat flux gauges are water-cooled.

\subsection{Supplemental and Boundary Condition Measurements}

\subsubsection{Total Heat Flux Across the Surface of the Pool -Total Heat Thermopile Flux Gauges}

The total heat transfer from the fire to the pool was measured by an array of wide angle $\left(180^{\circ}\right)$ heat flux gauges (Model 64-20SB-18-5MGO-120-20970K Schmidt-Boelter type water-cooled thermopile gauges measuring total heat flux with a range of 0 to 120 $\mathrm{kW} / \mathrm{m}^{2}$, Medtherm Corporation, Huntsville, AL). The sensing surface of each gauge will be placed at a nominal height approximately $\sim 10 \mathrm{~mm}$ above the surface of the liquid 
fuel. The gauges will be placed at radial locations spaced such that each gauge is in the center of a concentric ring of equal area to minimize uncertainty in integrating the total heat flux over the surface of the pool (the fuel regression pan used in earlier tests, see Table 2 and Figure 4 for instrumentation locations used in those tests, spectrometer ports will not be used in these tests). Duplicate gauges at the same radial distance from the pan center will be used to assess the degree of symmetry in the radial direction.

The gauges will be "cooled" using a hot oil recirculation bath to prevent soot collecting on the sensor surface caused by thermophoresis. The bath temperature will be maintained a few degree above the measured boiling temperature of each fuel (measured at $\sim 62^{\circ} \mathrm{C}$ for the azeotropic fuel). Inspection of the gauges before and after each test will be performed to verify clean sensor surface conditions.

Table 2 Location of pan heat flux gauge rings.

\begin{tabular}{|c|c|c|c|}
\hline ring number & inner radius $(\mathbf{m})$ & outer radius $(\mathbf{m})$ & area $\left(\mathbf{m}^{\mathbf{2}}\right)$ \\
\hline 1 & 0.000 & 0.408 & 0.524 \\
\hline 2 & 0.408 & 0.577 & 0.524 \\
\hline 3 & 0.577 & 0.707 & 0.524 \\
\hline 4 & 0.707 & 0.816 & 0.524 \\
\hline 5 & 0.816 & 0.913 & 0.524 \\
\hline 6 & 0.913 & 1.000 & 0.524 \\
\hline
\end{tabular}

\begin{tabular}{|c|c|c|c|c|c|c|}
\hline position \# & ring \# & Medtherm \# & theta & radius $(\mathbf{m})$ & $\mathbf{x}(\mathbf{m})$ & $\mathbf{y}(\mathbf{m})$ \\
\hline 1 & 1 & 7 & -90 & 0.289 & 0.000 & -0.289 \\
\hline 7 & 1 & 11 & 135 & 0.289 & -0.204 & 0.204 \\
\hline 2 & 2 & 10 & -150 & 0.500 & -0.433 & -0.250 \\
\hline 8 & 2 & 9 & 75 & 0.500 & 0.129 & 0.483 \\
\hline 3 & 3 & 2 & 150 & 0.645 & -0.559 & 0.323 \\
\hline 9 & 3 & 12 & 15 & 0.645 & 0.624 & 0.167 \\
\hline 4 & 4 & 1 & 90 & 0.764 & 0.000 & 0.764 \\
\hline 10 & 4 & 5 & -45 & 0.764 & 0.540 & -0.540 \\
\hline 5 & 5 & 6 & 30 & 0.866 & 0.750 & 0.433 \\
\hline 11 & 5 & 3 & -105 & 0.866 & -0.224 & -0.837 \\
\hline 6 & 6 & 8 & -30 & 0.957 & 0.829 & -0.479 \\
\hline 12 & 6 & 4 & -165 & 0.957 & -0.925 & -0.248 \\
& 1 & spec 1 & 15 & 0.183 & 0.178 & 0.044 \\
& 1 & spec 2 & 1 & 0.387 & 0.390 & 0.012 \\
& 3 & spec 3 & -110 & 0.675 & -0.221 & -0.640 \\
\hline
\end{tabular}




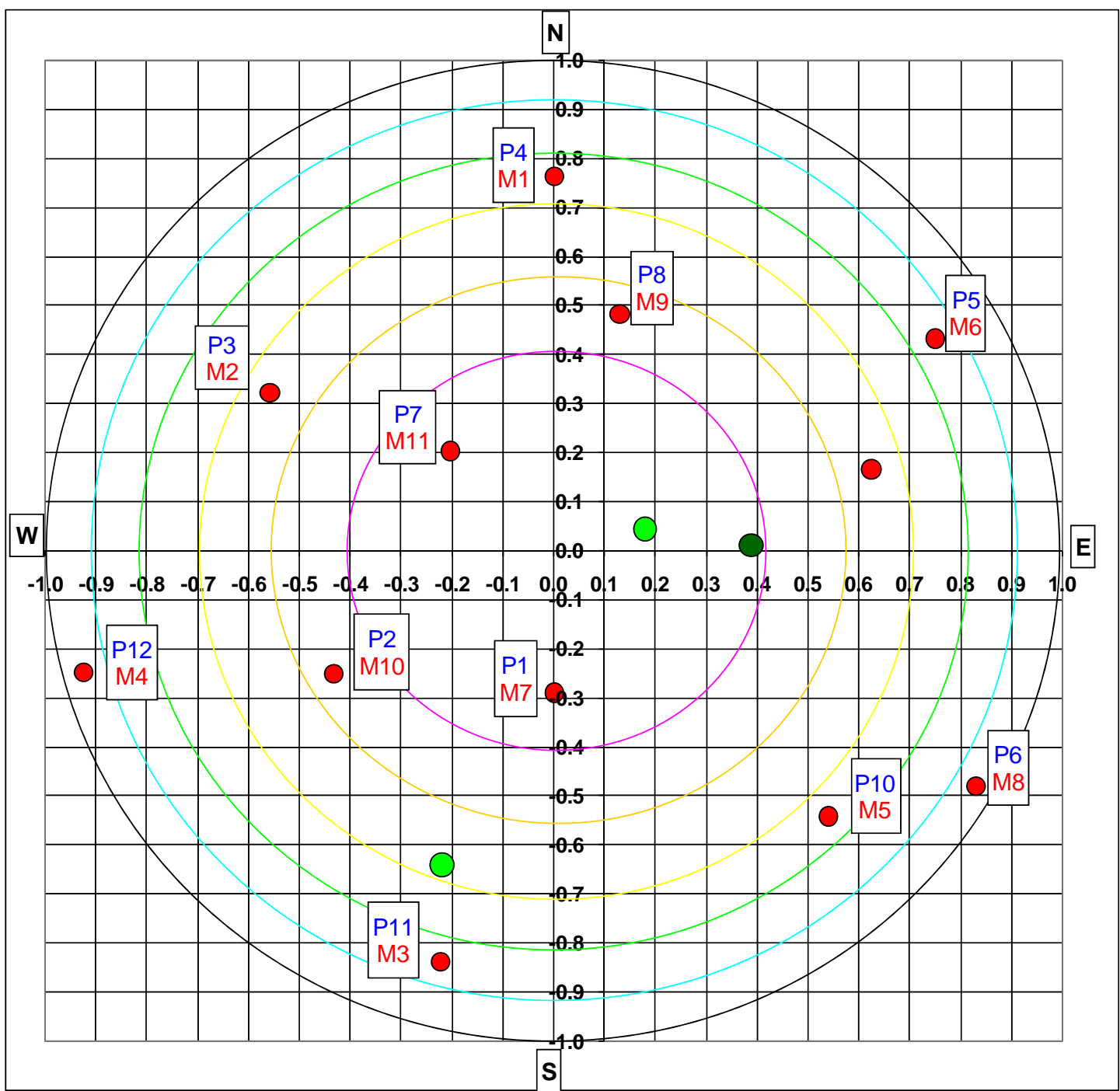

Figure 4 Locations of heat flux gauges.

\subsubsection{Flame topology (Height and Diameter) - Video and IR cameras}

The average flame height will be determined from visual data from a video camera in the FRH test cell. Prior to the test each position within the camera frame will be mapped to a height above the centerline of the fire using a stadia board. The flame height will be assumed to be the height at the centerline corresponding to the location within the camera frame in which the flame is visible at least $10 \%$ of the time. Both a visual and an IR camera will be employed for comparison. 


\subsubsection{Fuel Regression Rates}

The liquid level control system is shown in Figure 5. Fuel is supplied to the pan from a standard 270 gallon tote located outside the FRH test chamber. The tote sits on a scale (Doran Model XLS/ISAC 9000) with a $4 \mathrm{ft}$ by $4 \mathrm{ft}$ base to fit inside a spill pallet, manufactured by Doran Scales, Batavia IL. A positive displacement Alsco drum pump (model 2998 with 53 gpm (200 lpm) rated flow) draws fuel continuously out of the supply tank at a rate that is greater than the burning rate. The fuel that is not needed to maintain a constant amount of fuel in the pan is returned to the supply tank. The amount of fuel in the pan is inferred from differential pressure measurements made by a Rosemount Model 3051 differential pressure gauge and monitored by a Red Lion programmable controller. When the differential pressure measurement falls below the lower set point the controller opens a control valve (ASCO EF8210B054 1 inch solenoid valve) allowing fuel to be fed to the pan through a 3/4 in. (inner diameter) fuel rated hose. When the differential pressure reading reaches the upper set point the controller closes the control valve and the entire flow of fuel drawn out by the pump is simply returned to the supply tank. A second, identical Rosemount 3051 differential pressure gauge is used for data acquisition purposes. Differential pressure data are also obtained through the controller, but this data does not have the full resolution due to the output card on the Red Lion controller.

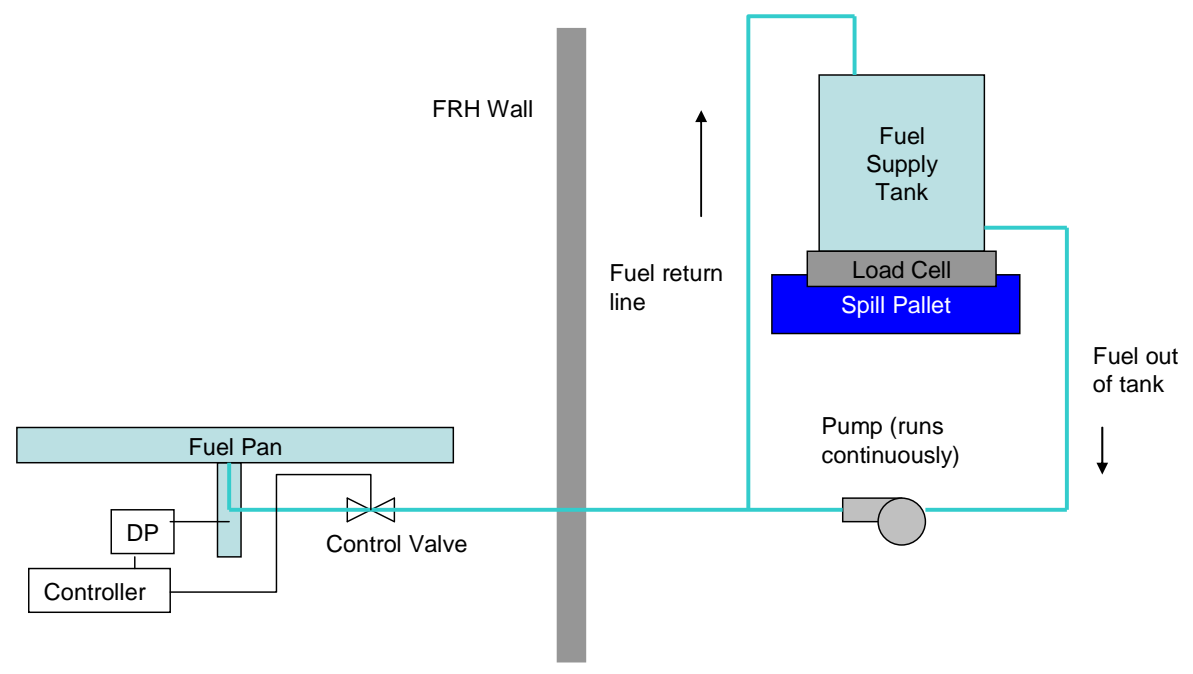

Figure 5 Schematic of the liquid level control system. 
To minimize the disturbances to the differential pressure readings caused by the inflow of fuel into the pan, the fuel should not be discharged into the pan in close proximity to the gauge. For best stability the differential pressure gauges are mounted on the neck of the drain pipe beneath the fuel pan. The fuel is fed up through the neck and then through about $20 \mathrm{ft}$ of perforated tubing to distribute the fuel inflow around the pan (not illustrated).

Since fuel is supplied to the pan over the course of a fire test, the fuel regression rate will be determined from the rate at which fuel is drawn out of the supply tank. A scale will measure the rate of fuel loss from the supply tank over the course of a test. The scale has a range of 0 to $2000 \mathrm{lbs}$ ( 0 to $909 \mathrm{~kg}$ ) and a resolution of $0.15 \mathrm{lb}(0.07 \mathrm{~kg})$. The mass loss rate from the pool is found directly from the change in mass of the supply tank with time. The fuel regression rate is found from the mass loss rate, the area of the fuel pan, and the density of the fuel.

\subsubsection{Liquid Level Control and Fuel Temperatures}

The liquid level and the temperature distribution across the depth of the pan in the fuel pan will be monitored through the use of a thermocouple rake. Thirty (30) thermocouples (type-K, mineral-insulated, metal-sheathed (inconel), 0.040 inch diameter) are mounted on a steel rake with yield positions in the fuel pan as indicated in Figure 6. Note the majority of the spacing is $1 \mathrm{~mm}$, to allow fine control of the fuel level. Figure 6 shows the nominal position of the thermocouples and also shows the position of the faces of the twelve (12) total heat flux gauges (thermopiles) mounted to the fuel pan.

For each test, the fuel DP controller is was set based on the estimated fuel regression rate ( $146 \mathrm{~g} / \mathrm{s}, 46.5 \mathrm{~g} / \mathrm{m}^{2} \mathrm{~s}$ for the azeotrope fuel in the $2 \mathrm{~m}$ pan). After fuel ignition, slight adjustments to the controller set point are performed to set the fuel level to the desired level. The liquid level is easily determined by plotting the temperatures from the thermocouple rake; with a temperature gradient for the fuel in the subcooled regime, at the boiling point (the fuel surface), and superheated fuel in the vapor dome above the liquid surface. 


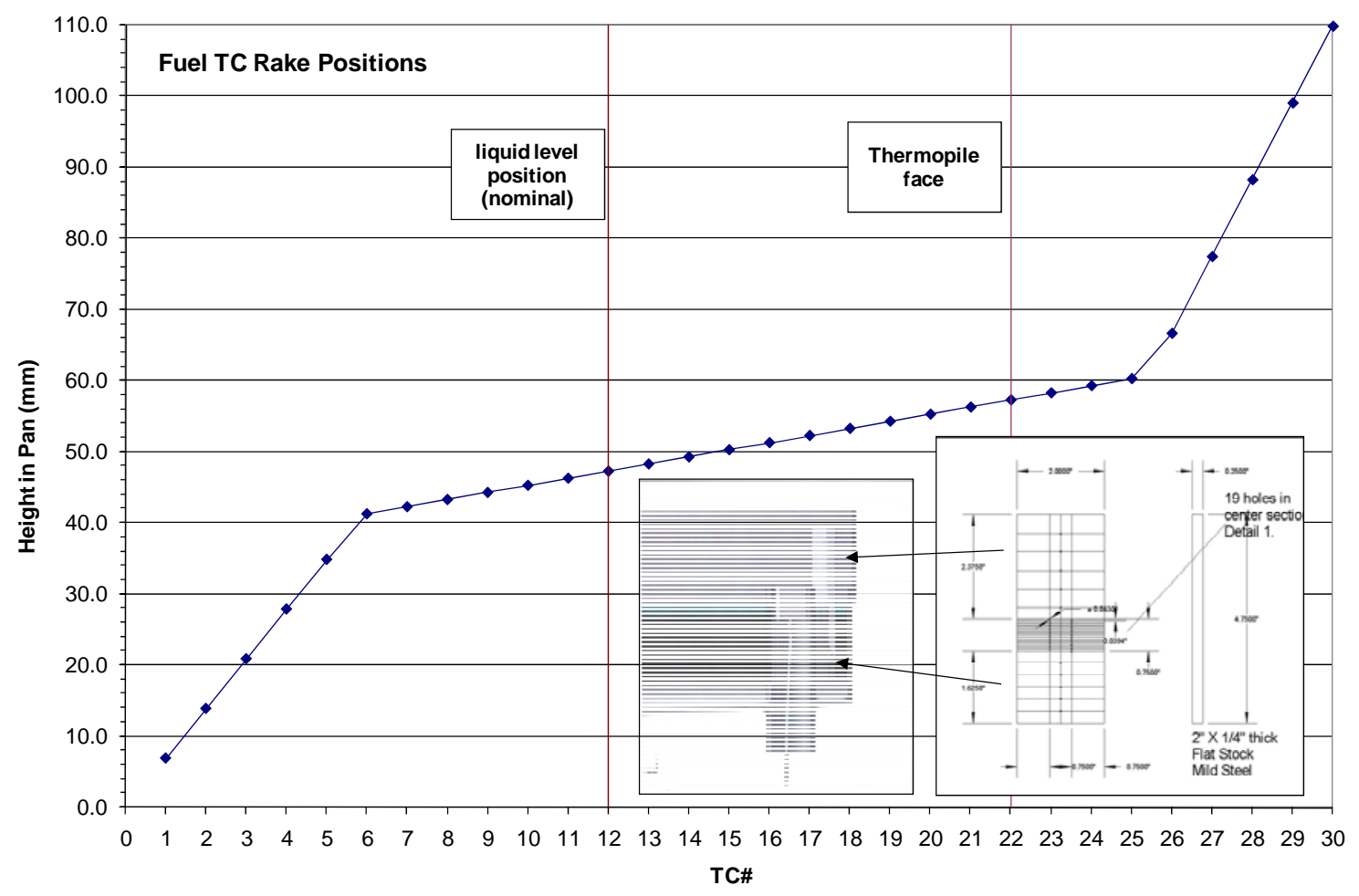

Figure 6 Thermocouple positions in fuel pan.

\subsubsection{Combustion Air Flow Rate and Temperature}

The coflow air supplied to FRH is controlled to maintain a constant flow rate at the desired value. A forced-draft fan forces air into the chamber at the specified flow rate. An induced-draft fan in the exhaust duct helps to draw air and combustion products out of the chamber and maintains the pressure at ambient levels. Both fans are computer controlled and the flow rate, fan speed, and current for each fan are logged. The air temperature is measured by a thermocouple in the basement of the FRH facility.

\subsubsection{Wall Temperatures}

The temperatures of the steel walls of the FRH chamber are measured by thermocouples mounted at heights of $1 \mathrm{ft}(30 \mathrm{~cm}), 10 \mathrm{ft}(3.04 \mathrm{~m}), 20 \mathrm{ft}(6.08 \mathrm{~m}), 30 \mathrm{ft}(9.12 \mathrm{~m})$, and $39 \mathrm{ft}$ $(12.16 \mathrm{~m})$ above the steel grating. The thermocouples are shielded from the radiation from the fire and the convective flow of the coflow air by a small piece of metal foil to 
minimize bias errors in the wall temperature measurement. These measurements are duplicated at four equally-spaced angular locations around the facility. The wall temperature measurements are of interest for imposed boundary conditions in validation simulations.

\subsubsection{Composition of Combustion Products in Overfire Region}

The composition of the combustion products above the fire will be monitored using a Combustion Gas Analyzer (CGA) in the chimney. The CGA (Land Instruments International, model FGA II) measures the concentrations of $\mathrm{CO}, \mathrm{CO}_{2}, \mathrm{O}_{2}, \mathrm{NO}, \mathrm{NO}_{2}$, $\mathrm{NO}_{\mathrm{x}}$, and $\mathrm{SO}_{2}$. Laser extinction measurements similar to those taken at the old FLAME facility [Jensen and Brown, 2004] are taken near the CGA and provide an estimate of the soot concentration, further extending the knowledge of the combustion products in the over-fire region. The temperature of the exhaust gases is measured by a thermocouple close to the soot probe and CGA locations in the exhaust duct.

\section{DESIGN OF EXPERIMENTS}

\subsection{Fuel Properties}

One fuel has been proposed; a liquid fuel mixture of 72.4\% methanol and $27.6 \%$ toluene, chosen because it lightly sooting (to allow combined CARS/LII measurements) and it is also an azeotrope; a mixture of two or more liquids in such a ratio that its composition cannot be changed by simple distillation. When an azeotrope is boiled, the resulting vapor has the same ratio of constituents as the original mixture. Table 3 presents selected properties and fire parameters using a $2 \mathrm{~m}$ diameter pool. 
Table 3 Fuel Properties

\begin{tabular}{|c|c|c|c|c|c|c|}
\hline & & & \multicolumn{2}{|c|}{$\begin{array}{l}\text { Literature Values } \\
\text { for Pure Fuels }\end{array}$} & & \multirow{2}{*}{$\begin{array}{c}\text { Calculated } \\
\text { Values for Fuel } \\
\text { Mixtures (using } \\
\text { mixture rules) } \\
\begin{array}{c}72.4 \% \text { Methanol } \\
27.6 \% \text { Toluene }\end{array} \\
\end{array}$} \\
\hline Properties & Properties & Units & \begin{tabular}{|l|} 
methyl \\
alcohol
\end{tabular} & toluene & & \\
\hline Name & Formula & - & $\mathrm{CH}_{4} \mathrm{O}$ & $\mathrm{C}_{7} \mathrm{H}_{8}$ & & $\mathrm{CH}_{4} \mathrm{O} / \mathrm{C}_{7} \mathrm{H}_{8}$ \\
\hline molecular weight & MW & 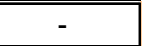 & 32.1 & 92.1 & & 39.7 \\
\hline $\begin{array}{l}\text { Boiling point } \\
\text { handbook }\end{array}$ & $\mathrm{T}_{\mathrm{b}}$ & $\mathrm{C}$ & 64.8 & 110.4 & & 71 \\
\hline smoke point & $I_{s}$ & $\mathrm{~m}$ & 0.281 & 0.005 & & 0.100 \\
\hline $\begin{array}{c}\text { heat of } \\
\text { vaporization }\end{array}$ & hv & $\mathrm{kJ} / \mathrm{kg}$ & 1101.0 & 360.0 & & 883 \\
\hline specific heat & $\mathrm{C}_{\mathrm{p}}$ & $\mathrm{kJ} / \mathrm{kg} \mathrm{K}$ & 2.37 & 1.67 & & 2.16 \\
\hline $\begin{array}{c}\text { heat of } \\
\text { gasification }\end{array}$ & hg & $\mathrm{kJ} / \mathrm{kg}$ & 1272 & 520 & & 1050 \\
\hline density & 1 & $\mathrm{~kg} / \mathrm{m}^{3}$ & 791.4 & 866.9 & & 814 \\
\hline $\begin{array}{c}\text { heat of } \\
\text { combustion } \\
\text { (measured) }\end{array}$ & ( hc & $\mathrm{kJ} / \mathrm{kg}$ & 19718 & 41630 & & 26080 \\
\hline $\begin{array}{c}\text { carbon monoxide } \\
\text { component }\end{array}$ & $\left(\mathrm{hc}_{\mathrm{CO}}\right.$ & $\mathrm{kJ} / \mathrm{kg}$ & 12900 & 9000 & & 11751 \\
\hline $\begin{array}{c}\text { carbon dioxide } \\
\text { component }\end{array}$ & $\left(\mathrm{hc}_{\mathrm{CO} 2}\right.$ & $\mathrm{kJ} / \mathrm{kg}$ & 14500 & 12100 & & 13793 \\
\hline $\begin{array}{c}\text { oxygen } \\
\text { component }\end{array}$ & $\left(\mathrm{hc}_{\mathrm{O} 2}\right.$ & $\mathrm{kJ} / \mathrm{kg}$ & 13400 & 12900 & & 13253 \\
\hline burning rate? & max m"-dot & $\mathrm{kg} / \mathrm{m}^{2} \mathrm{~s}$ & 0.015 & 0.075 & & 0.033 \\
\hline \begin{tabular}{|c|} 
incompleteness of \\
combustion
\end{tabular} & lch & - & 0.95 & 0.67 & & 0.87 \\
\hline radiant fraction & $U_{r}$ & - & 0.14 & 0.4 & & 0.22 \\
\hline smoke yield & $l_{s}$ & $g / g$ & 0.002 & 0.178 & & 0.053 \\
\hline Pan Diameter (m) & 2.00 & & & & Component & mole $\%$ \\
\hline Pan Area $\left(\mathrm{m}^{2}\right)$ & 3.14 & & & & Toluene & 0.13 \\
\hline & & & & & Methanol & 0.87 \\
\hline & & & & & & \\
\hline References: & & & & & \begin{tabular}{|c|} 
Component \\
Toluene
\end{tabular} & \# mole \\
\hline Archies new SFPE & ables & & & & Methanol & 17.8775 \\
\hline SFPE ed. 2, Table & -4.7 & & & & & \\
\hline SFPE ed. 2, Table & & & & & Component & mass $\%$ \\
\hline Industrial Fire Prot & ction Enginee & , Table 7.4 & & & Toluene & 0.29 \\
\hline SFPE ed. 2, Table & -4.19 & & & & Methanol & 0.71 \\
\hline Aviation Fuel Prope & ties, Coordina & Research & Council, I & ר. 1988 & & \\
\hline Distillation Range & $77-266 \mathrm{C}$ & & & & Component & Volume \% \\
\hline kerosene & 2 m complex & & & & & \\
\hline SFPE ed. 3, Table & -4.10 & & & & Toluene & 0.276 \\
\hline Galbraith Labs & & & & & Methanol & 0.724 \\
\hline
\end{tabular}




\subsection{Test Sequences / Number of Tests}

Approximately 30 tests are currently budgeted. Each test will have duration in the range of 30-40 minutes.

\subsection{Test Procedures}

The fire will be ignited with a propane igniter and allowed to burn for approximately 5 minutes before taking data to avoid the initial transient phase of the fire. Data from all instruments will be taken continuously at fixed locations throughout the test. There is a provision to move the fuel pan laterally during the test; however, the expectation is that it will not be moved in order to obtain meaningful statistics for the CARS and LII data. Filling of the pool to maintain a constant fuel level will be performed automatically throughout the test and the amount of fuel added will be monitored. Mean fuel regression rates are found from the time-averaged filling rates.

\section{DATA ACQUISITION}

The data acquisition system (DAS) for all standard fire and fuel measurements and facility instrumentation consists of a PC with a 16-bit data acquisition card connected to a National Instruments (NI) SCXI-1001 chassis. It has twelve NI SCXI-1102 cards with NI SCXI-1303 blocks for TCs and four NI SCXI-1104 cards with NI SCXI-1300 blocks for analog signals. This provides the ability to increase either analog signals or TC signals. Note that the SCXI-1001 presently holds 12 cards, yielding a total channel count of 384 channels if all slots are used for data acquisition. The system is upgradeable simply by adding an additional SCXI-1001 DAQ card and more multiplexer units (MUXs).

The data acquisition system can acquire temperature, heat flux, and pressure data. The integrity of all thermocouple channels is evaluated prior to each experiment with an Ectron thermocouple simulator, which inputs a controlled signal into each channel at the thermocouple device connection point and provides a check on the integrity of the channel hardware and software from that point to the final magnetic storage location. 
Data are sampled simultaneously for all channels, typically at $1000 \mathrm{~Hz}$ with an average value recorded at a rate of at least one sample per second, starting at least two minutes prior to the fuel ignition and continuing after burnout of the fire.

DAS for CARS - The CARS signal and pump/Stokes laser beams propagate through the second steel light pipe to a water-cooled enclosure housing collection optics. The CARS signal is separated from the high-intensity laser beams by a series of six dichroic mirrors and an interference filter with $>90 \%$ transmission. The CARS beam is transmitted by a $30-\mathrm{m}$ long fiber of $100-\mu \mathrm{m}$ core which is directly coupled to the $50-\mu \mathrm{m}$ entrance slit of a spectrograph located in the optical laboratory. Transmission through the fiber is greater than $80 \%$. The $0.75-\mathrm{m}$ long spectrograph with $1200 \mathrm{l} / \mathrm{mm}$ grating disperses the CARS signal onto a back-illuminated CCD camera with 95\% quantum efficiency. The observed peak $\mathrm{N}_{2}$ CARS signals were several million photoelectrons in room-temperature air and of order $10^{3}$ to $10^{6} \mathrm{e}^{-}$in the pool fire. Pixel saturation at low temperatures was avoided by using a deep-well-depth CCD portioned for readout into as many as 4 separate vertical bins such that less than $1 \%$ of single-shot spectra were impacted by saturation.

DAS for LII - Broadband incandescence from laser-heated soot particles was collected using the nitrogen-purged water-cooled probe discussed in the description of the LII instrument. The 10,000-element fiber optic bundle relays the LII image to a remotely located intensified CCD camera, located at the basement level of the FLAME facility. The intensified CCD is used to gate the LII images to $12 \mathrm{~ns}$ and supply a gain of several hundred. The LII detector is synched to the Q-switched Nd:YAG laser used to excite the LII using standard TTL-logic pulses. The data-acquisition rate for the simultaneous CARS and LII measurements is approximately $4 \mathrm{~Hz}$, and is dictated by the readout rate of the LII imaging camera, as the CARS detector "waits" for a trigger pulse from the LII camera to signal that an acquisition has begun. Both the CARS and LII CCD cameras are controlled using manufacturer provided data-acquisition software. The data are saved to disk in batches of 500 single-shot measurements and post-processed following the burn experiments. 
A formal checklist for conducting the test is created and used to record actions during the test event. The data from the instrumentation are organized via a Data Channel Summary Sheet and with sketches showing instrumentation location. This summary sheet contains a channel-by-channel listing of the instrumentation with details such as expected range, sampling rate, calibration date and source, instrument location, and the data sample rate. Post-test, all data are collected and converted to electronic format for purposes of archiving and dissemination via PC media (i.e., CD or equivalent).

\section{UNCERTAINTY ANALYSIS}

An uncertainty analysis for all measurements will be performed. The methodology typically follows Coleman and Steele [1999]. Bias errors which can be mathematically modeled, such as the bias error in thermocouple measurements in the fire, are algebraically added to the measurement and the uncertainty in the estimation of the bias is treated as a random error [Romero et al., 2005].

\subsection{Fuel Regression Rates}

The fuel regression is determined from the rate of change of mass of a fuel supply tank (previously described). The constant-level control system matches the averaged rate of mass loss from the supply tank to the averaged mass loss rate from the pool, but fuel is supplied to the pan at a rate greater than the regression rate when the control valve is open and is not supplied to the pan when the control valve is closed. The nature of the control system dictates that fuel regression measurements should be averaged over periods much larger than the typical cycle time between commanded signals to open the control valve. A cycling rate of about 2.9 cycles per minute was observed in methanol tests that were run during development of the constant level system.

The scale used for measuring the rate of change of fuel mass during the course of a test is resolved to $0.05 \mathrm{lb}(0.02 \mathrm{~kg})$ with an uncertainty of $\pm 0.06 \mathrm{~kg}$. Uncertainty in the averaged fuel regression rate decreases as a function of the time over which the results are averaged. For a $2 \mathrm{~m}$ pool using a fuel mixture of $72.4 \%$ methanol and $27.6 \%$ toluene, density $831 \mathrm{~kg} / \mathrm{m}^{3}$, with a fuel regression rate of $3.3 \mathrm{~mm} / \mathrm{min}$; the total mass loss from the 
fuel over a 30 minute span is $\sim 261 \mathrm{~kg}$. Since fuel is not supplied to the pan continuously, the uncertainty in the actual amount of fuel added to the pan will be assumed to be half the average mass added per cycle. The measured fuel fill cycle rate is 4.4 cycles per minute, yielding an uncertainty due to the unsteady fill rate of $\pm 0.51 \mathrm{~kg}$. If the uncertainty in the pan area, fuel density, and time between measurements are neglected, the total RSS combined uncertainty in the fuel regression rate measurement is \pm 0.01 $\mathrm{mm} / \mathrm{min}$ or $0.4 \%$.

\subsubsection{Total Heat Flux to Fuel Surface}

The manufacturer's stated uncertainty for the heat flux gauges used to measure the incident heat flux at the pool surface is $\pm 3 \%$. Nakos [2005] estimated that uncertainties in fire applications can be much larger ( $\pm 20 \%$ to $\pm 40 \%$ ), largely due to uncertainties in the convective component of heat transfer. The uncertainty in the measurement of heat flux to the fuel includes the gauge measurement uncertainty, the uncertainty in the net heat flux due to differences in temperature and reflectivity between the fuel and the gauge, and the uncertainty in the integration of heat flux over the pool surface area based on measured heat fluxes at a finite number of measurement locations. For the present work the temperature within the liquid fuel will be measured by a rake of thermocouples, but the temperature at the surface will be assumed to be the temperature of a saturated mixture at ambient pressure.

The sensitivity to limited data points in the radial dimension will be assessed by computing the total heat transfer in two ways. For the first method the pool surface area is divided into concentric rings of equal area within each of which a heat flux gauge is located. The total heat flux is calculated as the average of the heat flux gauge measurements, which is equivalent to assuming that the heat flux is constant across each ring at the value measured by the heat flux gauge. For the second method a continuous curve will be constructed which approximates the measured distribution of heat flux with radial position. The total heat transfer is computed from the analytic integral of the continuous curve. Final evaluation of the uncertainty will be performed post-test. 


\subsubsection{Temperature of Liquid Fuel}

An uncertainty analysis for thermocouple data acquisition systems in use at Sandia's Radiant Heat facility and the Lurance Canyon burn site has been performed by Nakos [2004]. The analyses apply to Type K, chromel-alumel thermocouples in MIMS thermocouple assemblies and other applications. Several DASs were analyzed, one Hewlett-Packard (HP) 3852A system, and several NI systems. The uncertainty analyses were performed on the entire system from the thermocouple to the DAS output file. Uncertainty sources include thermocouple mounting errors, ANSI standard calibration uncertainty for Type K thermocouple wire, potential errors due to temperature gradients inside connectors, extension wire effects, DAS hardware uncertainties including noise, common mode rejection ratio, digital voltmeter accuracy, $\mathrm{mV}$ to temperature conversion, analog to digital conversion, and other possible sources. Typical results for "normal" environments (e.g., maximum of 300 to $400 \mathrm{~K}$ ) showed the total uncertainty to be about $\pm 1 \%$ of the reading in absolute temperature. In high temperature or high heat flux ("abnormal") thermal environments, total uncertainties range up to $\pm 2-3 \%$ of the reading (maximum of $1300 \mathrm{~K}$ ). The higher uncertainties in abnormal thermal environments are caused by increased errors due to the effects of imperfect thermocouple attachment to the test item.

The ANSI standard uncertainty for Type $\mathrm{K}$ thermocouple wire is $2.2^{\circ} \mathrm{C}$ or $0.75 \%$ of reading (in ${ }^{\circ} \mathrm{C}$ ), whichever is greater. This uncertainty applies to the temperature of the thermocouple junction itself. Determination of the actual desired temperature (wall temperatures of an object or fluid temperatures) is subject to additional bias errors due to mounting. These bias uncertainties are very hard to accurately quantify, are application dependent, and are often the largest errors in the measurement system. For the present tests the bias error in the liquid fuel measurements will be assumed to be small compared to the thermocouple uncertainty. The thermocouple is in good thermal contact with the liquid, which has a thermal conductivity much greater than that of air. Furthermore, radiation errors, etc. are expected to be small within the liquid. The local liquid temperature is expected to vary slowly compared to the thermal response time of the thermocouple. The overall uncertainty of the liquid fuel temperatures will be assumed to 
be $\pm 3^{\circ} \mathrm{C}$, which adds some conservatism to the ANSI standard uncertainty over the range of temperatures at which the fuel is expected to exist in liquid form.

\subsubsection{Air Flow Rate and Temperature}

The air flow rate is measured by a Veltron II pressure and flow transmitter (Air Monitor Corporation, Santa Rosa, CA). The Veltron II calculates the air velocity and flow rate based on a differential pressure measurement. The differential pressure is measured to an accuracy of $0.1 \%$ of the natural span of the transmitter ( 10 inches of water). The uncertainty in the velocity due to the differential pressure uncertainty is approximately $\pm 3 \%$ at the chosen flow rate of $\sim 58,000 \mathrm{scfm}$. When the uncertainties due to nonuniformity in the velocity profile, tolerances on the duct dimensions, etc. are included the total uncertainty is estimated to be approximately $\pm 6 \%$ of the total flow rate.

Air temperature measurements are performed by thermocouples similar to those used in the liquid fuel measurements. The air temperature measurements are made inside a duct in a relatively cool environment in which convective heat transfer from the air to the thermocouple is expected to dominate, therefore the uncertainty in the air temperature will be assumed to be the same as the uncertainty in the fuel temperature measurements, $\pm 3^{\circ} \mathrm{C}$.

\subsubsection{Wall Temperatures}

Wall temperature measurements are made by thermocouples mounted to the steel walls of the FRH chamber. The thermocouples are in good thermal contact with the walls, which have a very high thermal conductivity. The thermocouples will be partially shielded from the radiation of the fire and convection from the cool coflowing air. Previous experience has shown that the walls remain relatively cool during tests due to their large thermal mass. The analysis of Nakos [2004] suggests that the maximum error is $\pm 1 \%$ of the reading (in K) for temperatures up to $400 \mathrm{~K}$. An uncertainty of $\pm 4^{\circ} \mathrm{C}$ will be assumed for the wall temperatures in the present tests. 


\subsubsection{Temperatures inside the Fire}

The second measurement technique for measuring gas temperatures inside the fire is CARS. Typical uncertainties in single-laser-pulse CARS temperature measurements in laboratory flames range from 3-5\%, with some reduction in uncertainty when the CARS spectrum is averaged over many laser pulses. Kearney and Grasser [2007] estimated that the single-shot CARS measurements taken with the instrumentation system developed for use in FRH have an uncertainty of 6.8\%. Uncertainties in temperature measurements for the fires in this test series can be expected to be somewhat larger due to the greater sooting propensity of the fuel mixtures in this test series.

\subsubsection{Heat Flux from the Plume Surface}

The incident radiative heat fluxes to objects outside the fire are measured by radiometers, calibrated after assembly by the manufacturer. The uncertainty in the measurement is the total uncertainty in the radiometer calibration. A typical radiative heat flux calibration uncertainty of $\pm 3 \%$ will be assumed.

\subsubsection{Spectral Transmission Coefficients in Fuel Vapor in Fires}

The manufacturer's stated uncertainty for the Spectraline ES-200 spectrometer is $\pm 0.5 \%$ of full range of the signal ( 0 to 10 Volts), which corresponds to the random error in the measurement. The accuracy of the intensity or the transmission coefficient measurement is then a function of the accuracy and appropriateness of the calibration. For transmission measurements the average voltage measured at the top of the vapor dome is used as a reference, and the ratio of the measured voltage lower in the vapor dome to the reference voltage is taken to be the transmissivity. With baseline intensity appropriate for a fire, the maximum and minimum reference voltages are estimated for the present analysis to be $1.5 \mathrm{~V}$ and $0.5 \mathrm{~V}$. The uncertainty in the transmissivity due to the random error in the recorded voltage is then \pm 0.03 transmissivity units at the maximum intensity and \pm 0.10 transmissivity units at the minimum intensity. If the uncertainty in the reference voltage is assumed to be $\pm 15 \%$, the overall uncertainties rise to \pm 0.15 and \pm 0.18 transmissivity units. 


\subsubsection{Average Flame Height}

The flame height is defined herein as the highest point at which a flame is visible at least $10 \%$ of the time. Images will be recorded on video from both a visual and an IR camera for comparison. Uncertainty in the actual height of the visible flame in an individual image is estimated to be approximately $10 \mathrm{~cm}$. Uncertainty in determination of the average flame height based on a minimum of 1000 video frames will be assumed to be equal to the uncertainty in determining the height of the flame within the frame.

\subsubsection{Combustion Products Composition}

The CGA resolves the concentrations of minor species CO, $\mathrm{NO}, \mathrm{NO}_{2}, \mathrm{SO}_{2}$ to $0.1 \mathrm{ppm}$. Concentration of $\mathrm{CO}_{2}$ is resolved to $1000 \mathrm{ppm}$ and $\mathrm{O}_{2}$ is resolved to $100 \mathrm{ppm}$. Uncertainties for all species except $\mathrm{O}_{2}$ are a function of the user-specified total range for that species. The uncertainties are given as $\pm 2 \%$ of the range for the calibration linearity, with additional components for zero drift and span drift over time. The uncertainty due to calibration is a fixed $\pm 2000 \mathrm{ppm}$ for $\mathrm{O}_{2}$. The drift contributions become comparable to the linearity contributions after approximately one month between calibrations. For the present work the overall uncertainties will be assumed to be $\pm 3000 \mathrm{ppm}$ for $\mathrm{O}_{2}$ and $\pm 3 \%$ of the full range for each of the remaining species.

Jensen and Brown [2004] estimated the total uncertainty in soot yield fraction for a soot probe similar to the one used in the present test series to be $\pm 26.0 \%$ of the measurement. The largest single contributor to the uncertainty was the uncertainty in the fuel regression rates, which was limited by low resolution in the regression measurements of \pm 0.5 $\mathrm{mm} / \mathrm{min}(\sim 20 \%)$ in their application. As previously discussed, uncertainty in fuel regression rates for the present test series will decrease as the averaging time increases and become small ( 2\%) over ten minute intervals. The total uncertainty in the present experiments based on an uncertainty of $\pm 5 \%$ in the fuel regression rate but otherwise with the same uncertainties as reported by Jensen and Brown [2004], is $\pm 17.4 \%$ of the measurement. 
Temperatures in the exhaust duct are measured by a thermocouple located near the CGA and soot probe. At this location the flow can be assumed to be relatively uniform and to vary slowly compared to the time response of the thermocouple. Furthermore, the heat transfer is expected to be dominated by convection due to the large flow rate and the assumed uniformity in temperatures throughout the duct. The uncertainty of temperature measurements in the duct is assumed to be the same as the uncertainty of the coflow air temperature measurements. 


\section{REFERENCES}

Coleman and Steele. Experimentation and Uncertainty Analysis for Engineers, Wiley \& Sons, 1999.

Jensen, K. A., and Brown, A. L., "Measurement of soot yield from JP-8 pool fires using light extinction,” INTERFLAM04, Edinburgh, Scotland, July 5-7, 2004.

Kearney, S. P., “Temporally resolved radiation spectra from a sooting, turbulent pool fire,” Proceedings of International Mechanical Engineering Congress and Exposition, November 11-16, 2001, New York, NY.

Kearney, S. P., and Grasser, T. W., "CARS thermometry in a 2-m-diameter methanol pool fire," $45^{\text {th }}$ AIAA Aerospace Sciences Meeting and Exhibit, 8-11 Jan., 2007, Reno, NV.

Nakos, J. T., "Uncertainty analysis of thermocouple measurements used in normal and abnormal thermal environment experiments at Sandia's Radiant Heat facility and Lurance Canyon burn site,” SAND2004-1023, April 2004, Sandia National Laboratories, Albuquerque, NM.

Nakos, J. T., "Uncertainty analysis of steady state incident heat flux measurements in hydrocarbon fuel fires," SAND2005-7144, December 2005, Sandia National Laboratories, Albuquerque, NM.

Orloff, L., and de Ris, J., "Froude modeling of pool fires," Proceedings of the $19^{\text {th }}$ Symposium (International) on Combustion, 1982, pp. 885 - 895.

Ricks, A. J., “Characterization of air flow in New FLAME / Radiant Heat,” Sandia internal memo to T. Blanchat, March 20, 2006.

Romero, V. J., Sherman, M. P., Johnson, J. D., Dempsey, J. F., Edwards, L. R., Chen, K. C., Baron, R. V., and King, C. F., "Development and validation of a component failure model," paper AIAA2005-2141, 46 ${ }^{\text {th }}$ AIAA/ASME/AHS/ASC Structures, Structural Dynamics, and Materials Conference, April 18-21, 2005, Austin, TX. 


\section{APPENDIX A: SPATIALLY RESOLVED TEMPERATURE AND SOOT MEASUREMENTS USING LASER DIAGNOSTICS}

\section{CARS TEMPERATURE-MEASUREMENT TECHNIQUE}

The physics of the dual-pump CARS approach employed at FLAME, are summarized in the energy level diagrams shown in Fig. 2. The center frequency of the broadband Stokes dye-laser source is tuned so that the pump-1/Stokes frequency difference, $\omega_{1}-\omega_{\mathrm{s}}$, is coincident with the vibrational Raman frequencies of $\mathrm{N}_{2}$; this tuning induces an oscillating polarization (dipole) in the measurement volume that scatters the $\omega_{2}$ photons to deliver a CARS signal beam at $\omega_{\text {CARS }}=\left(\omega_{1}-\omega_{s}\right)+\omega_{2}$. For measurements in sooting flames, a tunable narrowband dye laser is used to scan the frequency $\omega_{2}$, which positions $\omega_{\text {CARS }}$ in a portion of the visible spectrum that is free from strong electronic- and Ramanresonant interference from laser-produced $\mathrm{C}_{2}$ and olefinic hydrocarbon species. In our measurements, a pump-2 wavelength of $\lambda_{2}=561.14 \mathrm{~nm}$ is used to position the $\mathrm{N}_{2} Q$ branch signature near $496.2 \mathrm{~nm}$, and tune the $\omega_{2}-\omega_{\mathrm{s}}$ frequency difference to drive Raman polarizations in $\mathrm{CO}_{2}, \mathrm{H}_{2}$, and $\mathrm{O}_{2}$ that scattered $\omega_{1}$ photons to yield additional CARS signatures from these species in close spectral proximity to the $\mathrm{N}_{2}$ signature. With this approach, temperature is determined from the shape of the $\mathrm{N}_{2} Q$-branch and gasphase species information from relative heights of the $\mathrm{N}_{2}, \mathrm{CO}_{2}, \mathrm{H}_{2}$, and $\mathrm{O}_{2}$ peaks.

A dual-pump CARS instrument has been fielded at FLAME, as shown in Fig. 3. A frequency doubled, Q-switched Nd:YAG laser operating at $10 \mathrm{~Hz}$ supplies 1,700 mJ per 8-ns pulse at a wavelength of $532 \mathrm{~nm}$. The Nd:YAG system provides sufficient energy to pump both the narrowband tunable dye laser and the broadband Stokes dye source, while 
also supplying the pump-1 beam to the CARS process. The broadband Stokes laser output is optimized for probing of the $\mathrm{N}_{2}$ molecule. The narrowband tunable dye source utilizes Rhodamine 590 dye in methanol to supply pump-2 radiation at $561.14 \mathrm{~nm}$.

The pump and Stokes beams are aligned in the folded BOXCARS configuration, shown in Fig. 2, and this phase-matched beam configuration is mirror coupled to the FLAME test bay. Fine-scale alignment of all three laser beams was provided by mounting a single turning optic in each beam line with a high-precision tip-tilt mount (Newport \# 610) atop a micrometer-driven linear translator. These mounts permit optimization of the CARS signal-to-noise (SNR) as they enable us to make $\mu$ radian-scale adjustments to the beam paths while observing the growth of the CARS signal. Inclusion of these high-precision mounts into the instrument is crucial because the 11-m path length between the CARS measurement volume and the laboratory optical tables greatly amplifies any laboratory adjustments.

The laser beams propagate $\sim 8.5 \mathrm{~m}$ across the facility to an $f=1000$-mm singlet beamcrossing lens housed in one of the steel light pipes, shown in Figure 4. The CARS measurement volume is an ellipsoid with 100- to $200 \mu \mathrm{m}$ minor-axis diameter $\times \sim 5$-mm minor-axis length. The CARS signal and pump/Stokes laser beams propagate through the second steel light pipe to an $f=1000$-mm collimating lens, and the signal is separated from the high-intensity laser beams by a series of six dichroic mirrors and an interference filter with $>90 \%$ transmission. The CARS beam is transmitted by a $30-\mathrm{m}$ long fiber of $100-\mu \mathrm{m}$ core which is directly coupled to the $50-\mu \mathrm{m}$ entrance slit of a spectrograph located in the laser laboratory adjacent to the FLAME test bay. 
Temperatures were derived from the $\mathrm{N}_{2}$-containing portion of our CARS spectra by least-squares fitting to theoretical calculations using the Sandia CARSFT code (Palmer, 1989) with the dual-pump CARS convolution equations summarized by Hancock et al., 1997. Fitting parameters included: (1) temperature, (2) a vertical offset that compensated for shot-to-shot variability in optical background, and (3) the $\mathrm{N}_{2}$ mole fraction, which was used to adjust the relative importance of the resonant to nonresonant CARS signals, as the nonresonant bath-gas contribution varied on a shot-to-shot basis in the turbulent pool-fire. Sample nitrogen CARS spectra from a sooting methanol/toluene pool fire (Kearney et al., 2009) are provided in Fig. 5, with both measured and best-fit theoretical spectra shown in the Figure. The temperature dependence of the nitrogen spectra is clearly illustrated. At "low” temperatures (426 and $741 \mathrm{~K}$ ), a single $\mathrm{N}_{2}$ peak is observed; this peak represents signal from the vibrational ground state of nitrogen, with a peak width that becomes wider as the available rotational levels "fill in" with increasing temperature. At higher temperatures (1301 and $1731 \mathrm{~K})$ a second peak appears in these spectra, which represents CARS signal arising from vibrationally excited nitrogen, the width of this "hot band" gets progressively larger with increasing temperature as well. Each spectrum in Fig. 5 represents a single-laser-shot temperature measurement from a measurement volume of $8 \times 10^{-5} \mathrm{~cm}^{3}$ and 10-ns time resolution. The CARS temperature data were determined to be accurate to within $1 \%$ and precise to within $6 \%$ of the measured temperature using measurements in a controlled-temperature tube furnace (Frederickson et al., 2009) and an adiabatic flat-flame burner (Kearney and Grasser, 2007). 


\section{SOOT-MEASUREMENT TECHNIQUE}

The LII approach for soot-volume-fraction measurement is illustrated in Fig. 6. The beam from a high-intensity pulsed Nd:YAG laser is used to form a thin sheet of light, which is partially absorbed by in-flame soot. The absorbing soot particles are rapidly heated to temperatures near their vaporization point, in the vicinity of 4000-5000 K. The $T^{4}$ dependence of soot thermal emission causes the incandescent high-temperature soot to emit well in excess of the nascent soot background at $\sim 1400 \mathrm{~K}$, and fast-gating intensified CCD cameras are used to record the LII signal on short time scales. Emission from the laser-heated soot has been shown (Santoro and Shaddix, 2002) to be proportional to the total volume of soot contained within the probing laser sheet and can, therefore be exploited for measurements of the average soot-volume fraction within the laser measurement volume.

A schematic of our LII optical system is shown in Fig. 7. The LII system has been designed to operate in tandem with our dual-pump CARS instrument. The bulk of the laser-sheet forming optics are located in a laser laboratory, and located $9 \mathrm{~m}$ or more from the fire measurement location. LII is generated using the 1064-nm fundamental of a second Q-switched Nd:YAG laser, operating at $10 \mathrm{~Hz}$ with a maximum output of $800 \mathrm{~mJ}$ per 10-ns pulse. A combination of a half-waveplate/polarizer assembly and dielectric attenuators are used to control the infrared pulse energy delivered to the experiment. Use of the infrared wavelength for LII eliminated laser-induced fluorescence background from polycyclic aromatic hydrocarbons and minimized interference from laser-produced $\mathrm{C}_{2}$ and other carbon species. The laser output coupler is a Gaussian reflector designed to produce a uniform-intensity spatial beam profile, and 5-mm-diameter teflon aperture was 
placed at the output of the laser to select only the central $50 \%$ of the laser beam. A Galilean telescope is used to expand the laser beam to a diameter of $\sim 15 \mathrm{~mm}$ and to adjust the location of the laser-sheet beam waist in the pool fire. Laser sheet forming is provided by a $f=-5000$-mm focal-length plano-concave cylindrical singlet lens, located $\sim 10 \mathrm{~m}$ from the measurement volume, and a $f=+1000-\mathrm{mm}$ spherical singlet housed in a water-cooled enclosure at the edge of the 2-m-diameter liquid fuel pan. These optics provide a 5-mm high $\times 1$-mm thick laser sheet for LII imaging which is aligned so that the laser-sheet center is coincident with the CARS measurement volume. Large focal lengths are used to provide a long beam-waist region that minimizes variation in lasersheet thickness across the detection optics field of view, and to place the first sheetforming element into the system prior to combining the LII and CARS laser beams in the remotely located laser lab.

Incandescence from laser-heated soot particles is collected normal to the infrared laser sheet by a water-cooled optical probe, shown schematically in Fig. 7. The LII collection optics are housed within the triple-walled, 2-m-long stainless-steel water jacketed probe (101.6-mm OD; 50.8-mm ID). The water-cooled probe extends into the fire plume and the temperature of the collection optics space does not exceed $30{ }^{\circ} \mathrm{C}$ during burns of 20-30 minute duration. An uncooled, nitrogen-purged cone is mounted at the fire end of the water jacket. The cone is uncooled to minimize the thermal intrusion near the LII measurement volume. The cone half angle is 8 degrees, which exceeds the f/4 aperture of the LII collection optics and minimally degrades the signal collection efficiency. A low-velocity nitrogen purge minimizes soot accumulation inside the cone, which eliminates soot deposition on the collection optics and limits the thickness of 
signal-trapping soot layer between the LII laser sheet and probe to the 38-mm space between the end of the cone and the laser sheet. The collection-optics are packaged in a mild-steel assembly which is mounted inside the water-cooled section of the probe. Infrared-reflecting and absorbing windows are used to minimize heating of the optics package by direct thermal radiation. Unit-magnification relay imaging of the LII measurement volume onto the face of a 1-cm square fiber-optic bundle is provided by two achromatic doublet lenses of 200-mm focal length and 50.8-mm diameter. The relay lens pair collects the LII signal at $f / 4$ with an estimated depth of field of better than $1 \mathrm{~mm}$. The fiber-optic bundle is $4.6 \mathrm{~m}$ long, with $10-\mu \mathrm{m}$ core optical fibers (1M elements) of 0.63 numerical aperture, and relays the LII image to the basement of FLAME, where the fiber output is imaged onto a gated, intensified CCD camera at $f / 2.8$ and near-unit magnification using a 105-mm Nikon glass camera lens. Observation of white light imaged through the collection optics and emerging from the fiber bundle indicated minimal overfilling of the camera lens.

The detector is gated on promptly with the arrival of the laser pulse and a gate width of $12 \mathrm{~ns}$ is used for broadband detection of the LII signal over the full 350- to $700-\mathrm{nm}$ bandpass of the glass lens and image-intensifier combination. Broadband detection was used to maximize the single-shot LII signal in this case, at the expense of some sensitivity to emission from laser-produced $\mathrm{C}_{2}$ and other photofragments resulting from the soot vaporization process.

Calibration of the measured LII signal for soot volume fraction is performed via laser-light extinction measurements in a laminar $\mathrm{C}_{2} \mathrm{H}_{4} /$ air diffusion flame. The calibration burner is a 12.7-mm-diameter fuel tube embedded in a 152-mm square ceramic 
honeycomb matrix for conditioned coflow air. The attenuated 532-nm pump beam from our dual-pump CARS instrument was used for the light-extinction measurements. The 532-nm extinction laser beam was focused to $\sim 100 \mu \mathrm{m}$ diameter at the fuel tube and aligned coincident with the LII laser sheet. The 10-ns extinction laser pulses were terminated onto a frosted-glass diffuser, which was viewed by a fast silicon photodiode, whose output was sensed by a gated BOXCAR integrator that was remotely located in the laser laboratory. Discrimination against background flame emission was achieved by inserting a neutral density filter of 3.0 between the photodiode and the flame and by gating the BOXCAR integration of the photodiode pulses to $100 \mathrm{~ns}$ or less. An additional photodiode/BOXCAR assembly was simultaneously used to monitor shot-to-shot fluctuations in pulse energy of the Nd:YAG laser which supplied the extinction laser beam. Both BOXCAR outputs were averaged for 5 seconds on a digital oscilloscope and several of these averages were recorded over the course of the calibration measurements. The time-averaged 532-nm light extinction, $I / I_{0}$, was computed from,

$$
\frac{I}{I_{o}}=\frac{V_{1}}{V_{2}} \frac{V_{2, o}}{V_{1, o}},
$$

where $V_{1}$ and $V_{2}$ are the averaged BOXCAR outputs for the extinction and laser-reference photodiodes, respectively, and the "o" subscripts indicates a reference measurement taken without the calibration flame in the beam path. Absorptive neutral-density filters of known attenuation were inserted in the beam path in place of the calibration flame to estimate the uncertainty of the light-extinction measurement, which was better than $\pm 2 \%$ at the levels of laser-beam extinction observed in the calibration flame. 
From the Beer-Lambert law, we can relate light extinction through the calibration flame to the soot-volume-fraction, $f_{v}$, distribution along the beam path as,

$$
\frac{I}{I_{o}}=\exp \left(-\frac{K_{e}}{\lambda} \int_{0}^{L} f_{v} d x\right),
$$

where $\lambda=532 \mathrm{~nm}$, and $K_{e}$ is the dimensionless extinction coefficient of soot. If we note the proportionality of the measured LII signal (in detector counts) to soot volume fraction, $f_{v}=C S_{\text {LII }}$, and rearrange Eq. 2 to solve for $C$ then,

$$
C=-\frac{\lambda}{K_{e}} \frac{\ln I / I_{o}}{\int_{o}^{L} S_{L I I} d x} .
$$

We evaluate the integral in Eq. 3 over using 25-shot-averaged LII data from the calibration flame from a region coincident with a Rayleigh scattering image from the 532-nm extinction laser beam, shown in Fig. 8.

Quantitative LII results from the laminar diffusion flame and a 30\% toluene / 70\% methanol pool fire are shown in Figs. 9 and 10. The results for the diffusion flame have been averaged over 25 single-shot LII realizations in the steady laminar flame system. Each pixel in the 2-D pool-fire image data in Figure 10 represent soot measurements in a $2.5 \times 10^{-6} \mathrm{~cm}^{3}$ volume with12-ns time resolution. 


\section{REFERENCES}

Frederickson, K., Kearney, S.P., Luketa, A., Hewson, J.C., and Grasser, T.W., "DualPump CARS Measurements of Temperature and Oxygen in a Turbulent Methanol-Fueled Pool Fire,” submitted to Combustion Science and Technology, 2009.

Hancock, R. D., Schauer, F. R., Lucht, R. P. and Farrow, R. L. (1997) Dual-Pump Coherent Anti-Stokes Raman Scattering Measurements of Nitrogen and Oxygen in a Laminar Jet Diffusion Flame. Applied Optics, 36(15), 3217.

Kearney, S.P. and Grasser, T.W., "CARS Thermometry in a 2-m-Diameter Methanol Pool Fire,” AIAA 2007-872, Aerospace Sciences Meeting, Reno, NV.

Kearney, S. P., Frederickson, K. and Grasser, T. W. (2009) Dual-Pump Coherent AntiStokes Raman Scattering Thermometry in a Sooting Turbulent Pool Fire.

Proceedings of the Combustion Institute, 32, 871.

Palmer, R. E. (1989) The CARSFT Computer Code for Calculating Coherent Anti-Stokes Raman Spectra: User and Programmer Information, SAND89-8206, Sandia National Laboratories, Livermore, CA.

Santoro, R. J. and Shaddix, C. R., (2002) "Laser-Induced Incandescence," in Applied Combustion Diagnostics, K. K. Hoinghaus and J. B. Jeffries, Eds.: Taylor and Francis, pp. 252-286. 


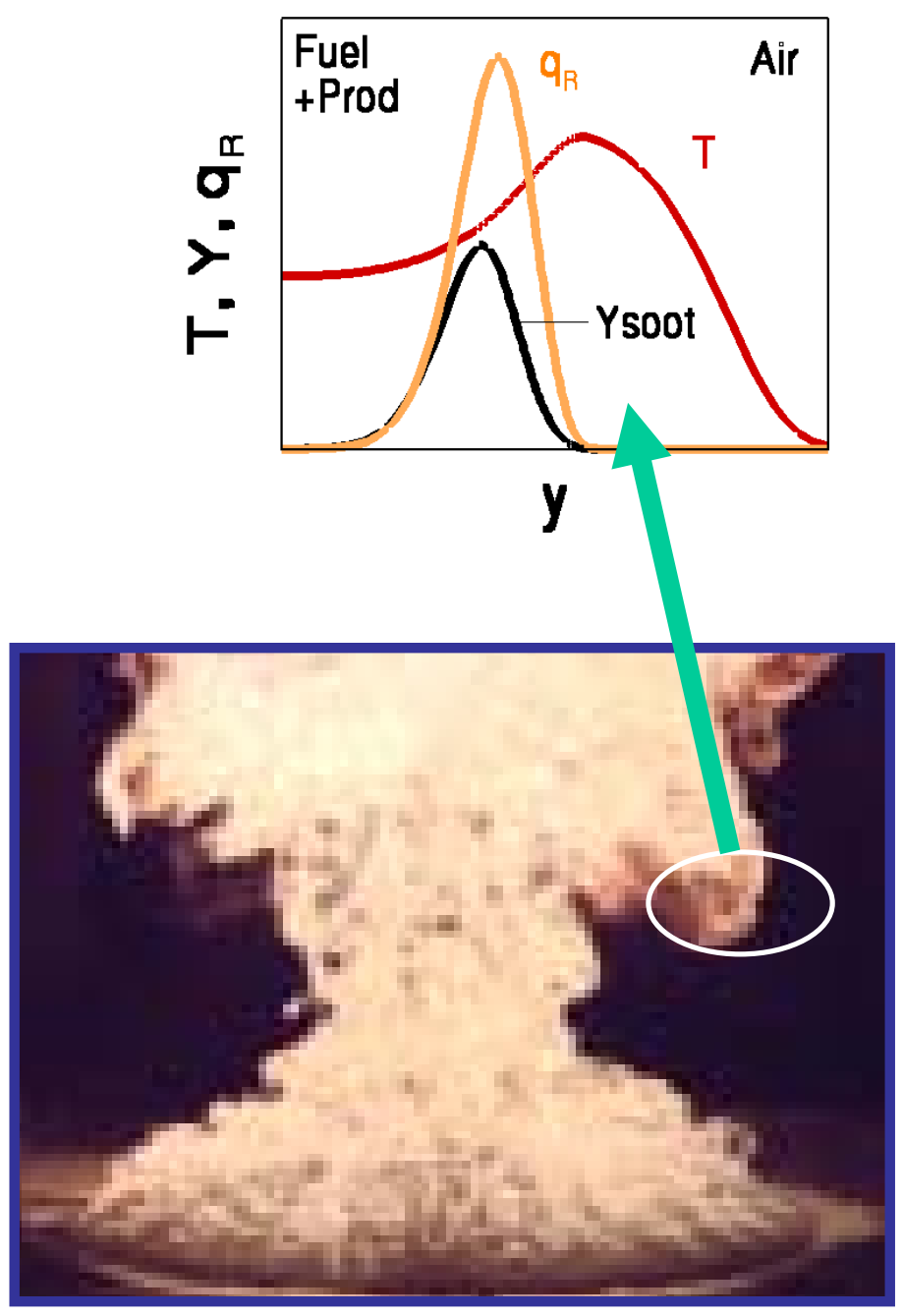

Figure 1 - Soot radiative emission in hydrocarbon fires. The fire plume is composed of individual turbulent flames with a given temperature and soot profile. The nonlinear nature of the soot emission term makes the relative position of the temperature and soot curves, or the spatially resolved temperature/soot correlation, important in predicting soot emission and total fire heat flux. 


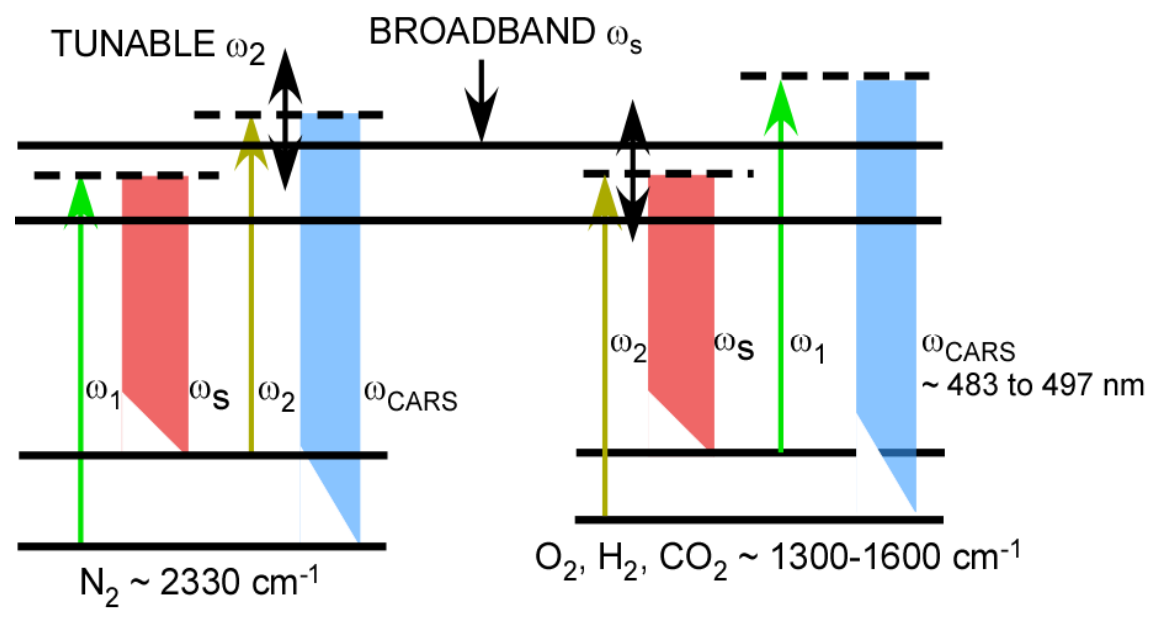

(a)

$$
\omega_{\mathrm{CARS}}=\left(\omega_{1}-\omega_{\mathrm{s}}\right)+\omega_{2}
$$

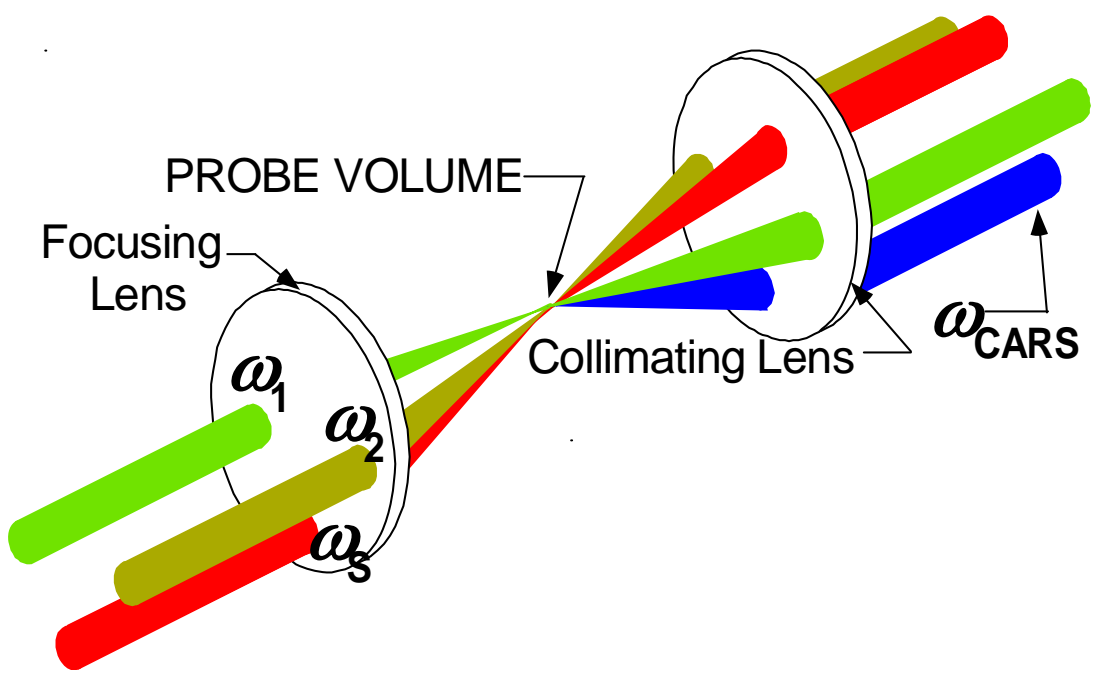

(b)

Figure 2 - CARS energy level diagrams (a) and phase-matched laser-beam arrangement (b). 


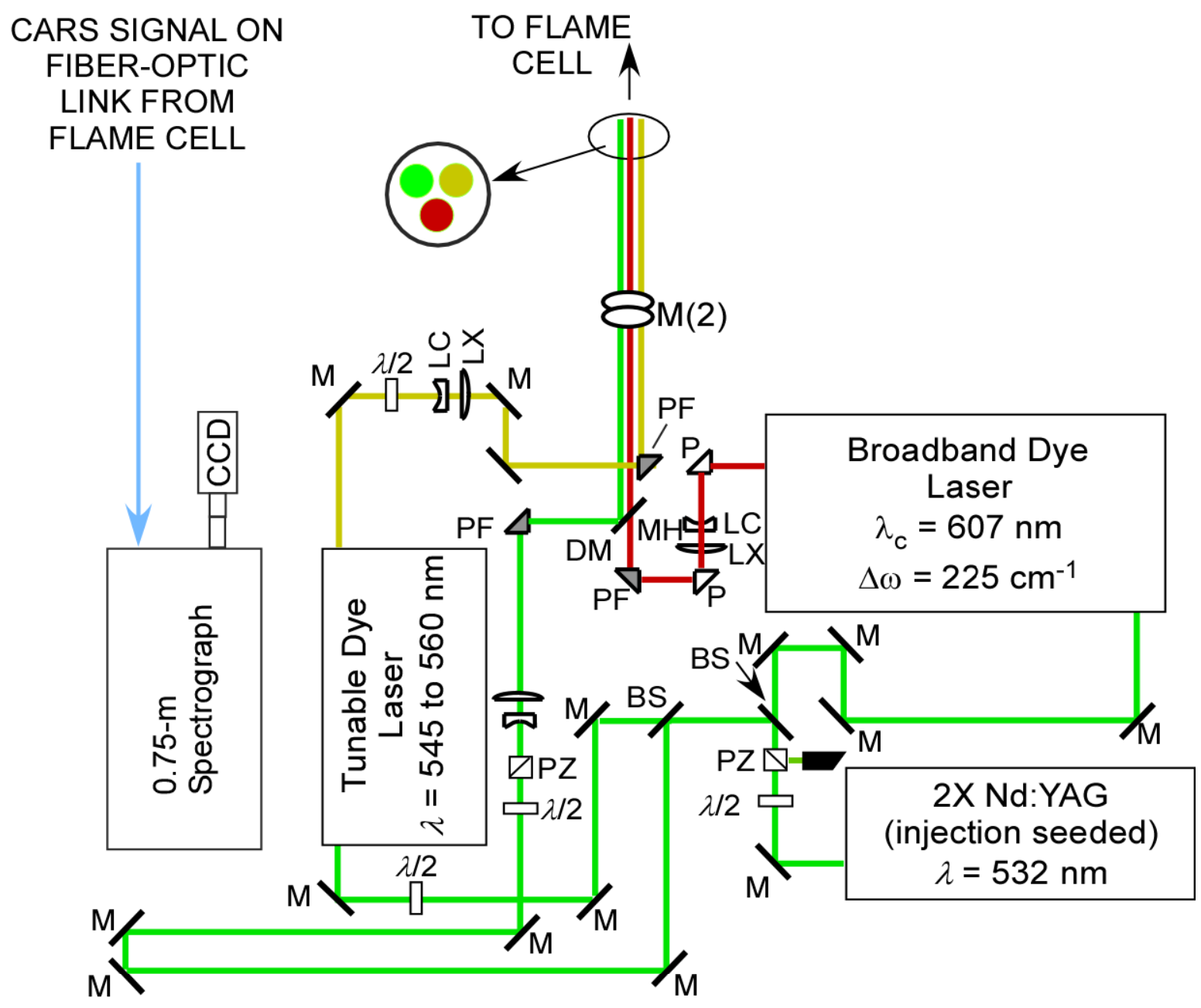

Figure 3 - Optical layout of the CARS instrument. Legend is as follows: (BS) beamsplitter; (M) dielectric turning mirror; (M2) mirror periscope; (LC) concave lens; (LX) convex lens; (P) turning prism; (PF) turning prism on fine-adjust mount; (PZ) polarizer; $(\lambda / 2)$ half-wave rotator. 

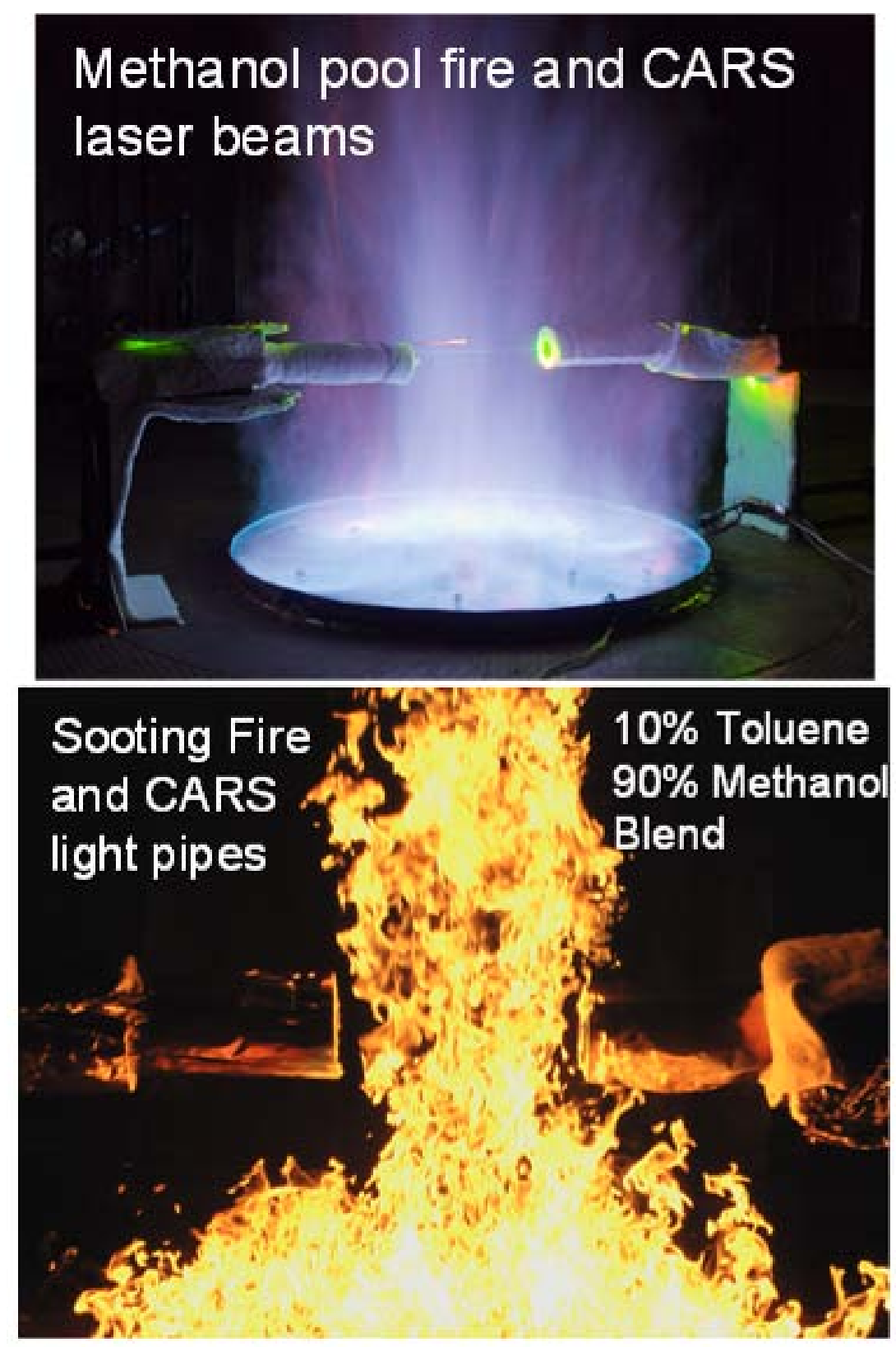

Figure 4 - Methanol (top) and sooting methanol/toluene (bottom) pool-fire experiments at FLAME. The beam-delivery tubes, or "light pipes" for the laser diagnostic measurements are shown in the figure. These tubes also house and protect nearby focusing and collection optics for the laser-diagnostic probes. 


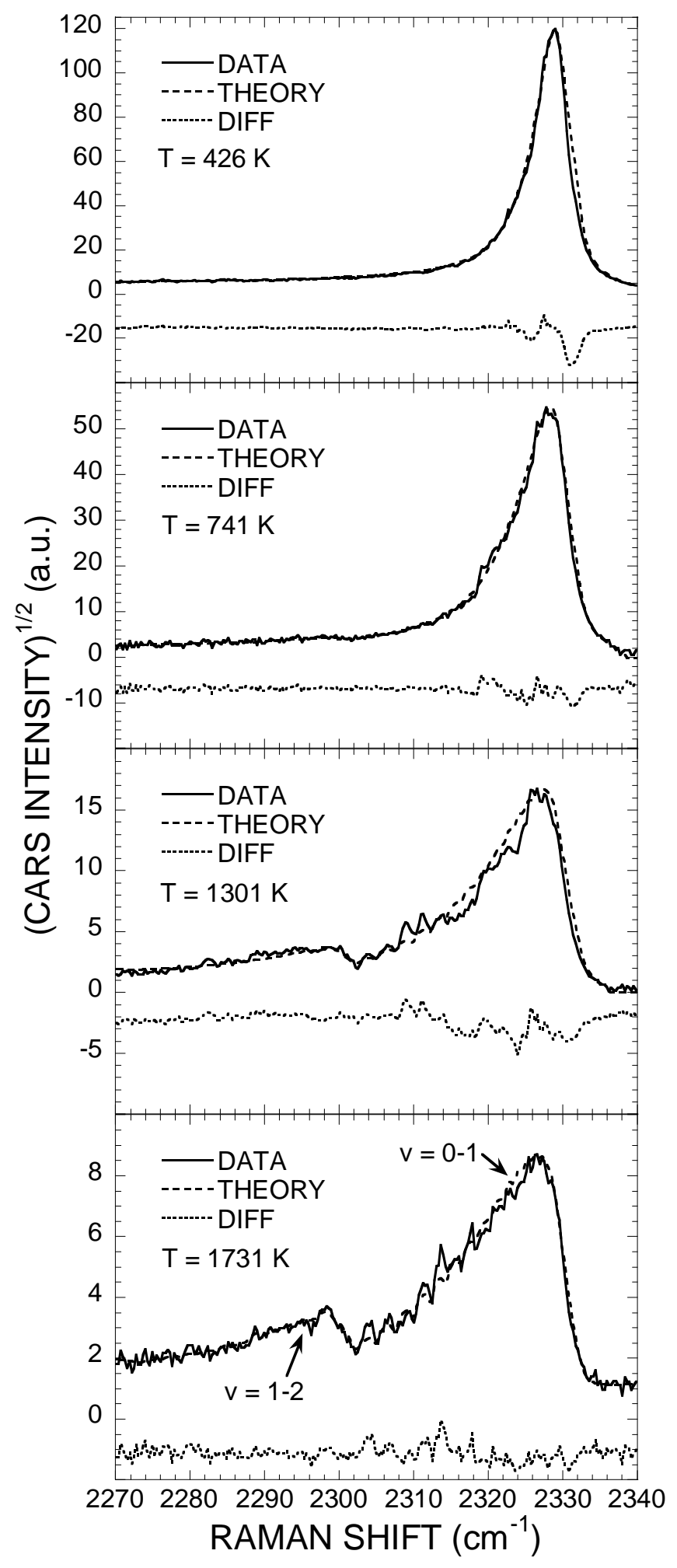

Figure 5 -- Representative fits to the $\mathrm{N}_{2}$-containing portion of single-shot dual-pump CARS spectra obtained from a sooting methanol/toluene pool fire. 


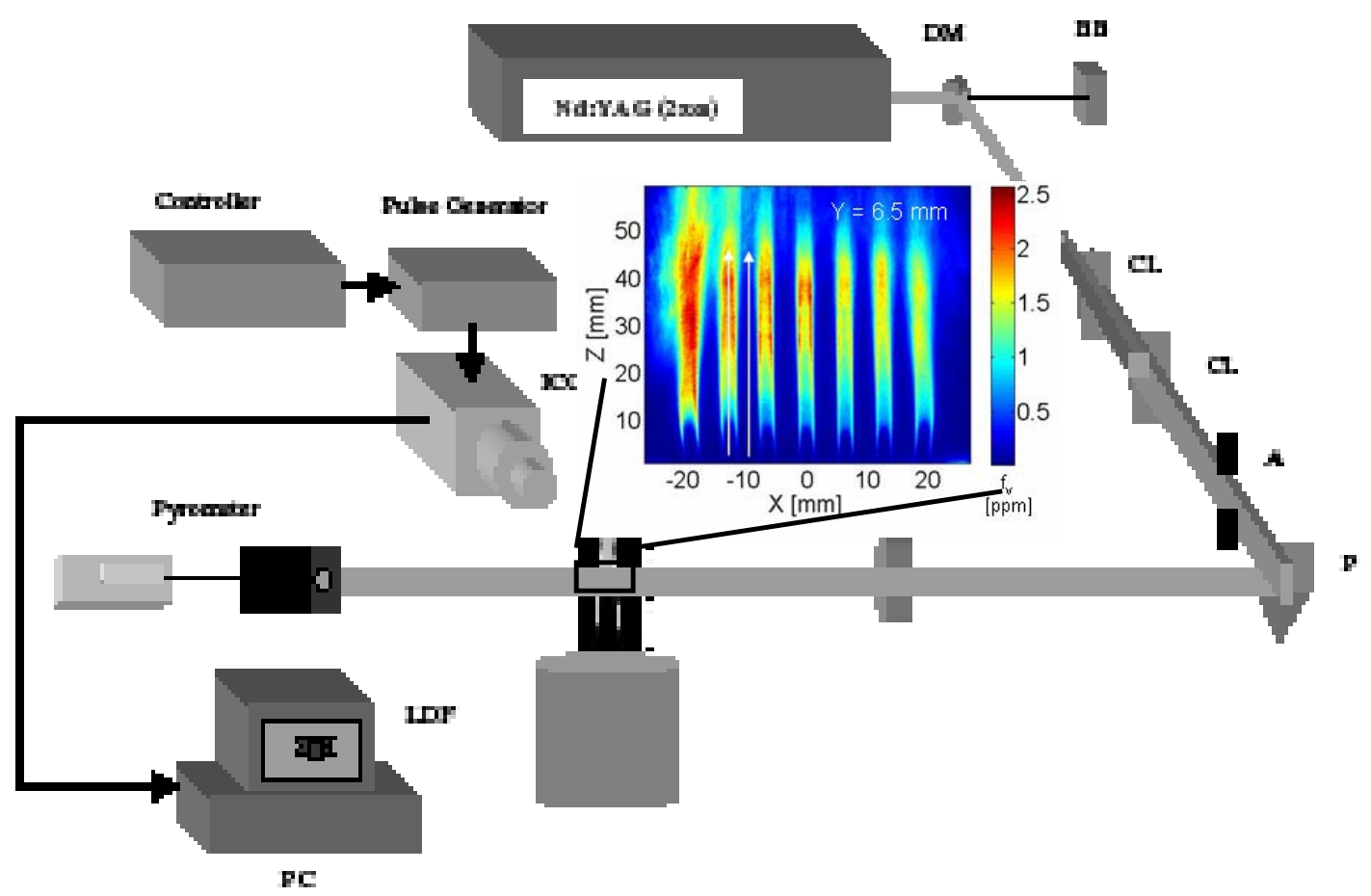

Figure 6 - Illustration of the LII measurement approach for soot-volume-fraction imaging (Santoro and Shaddix, 2002). 


\section{Uncooled}

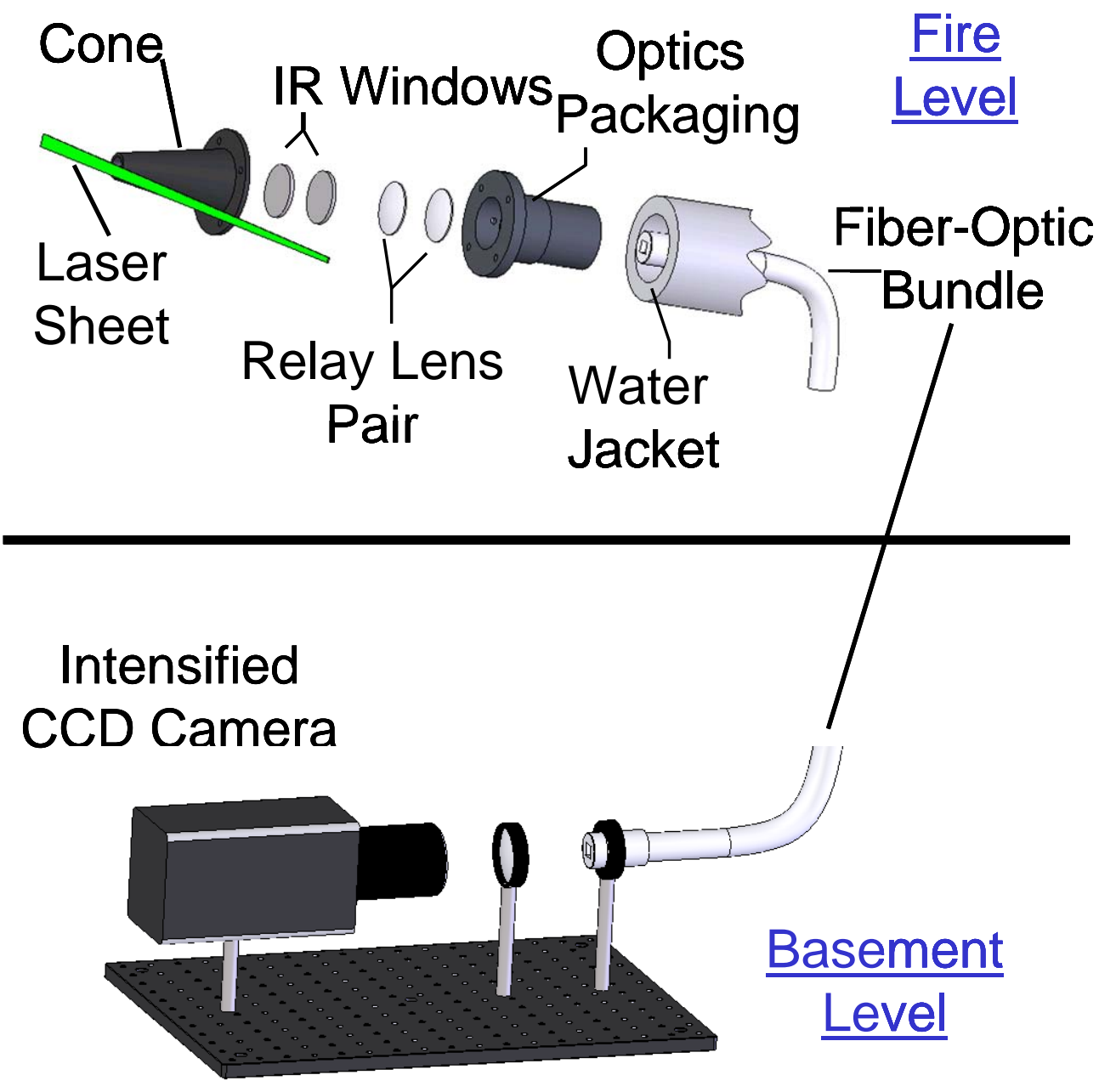

Figure 7 - LII collection optics in FLAME test bay. 


\section{Extinction \\ Laser Beam}
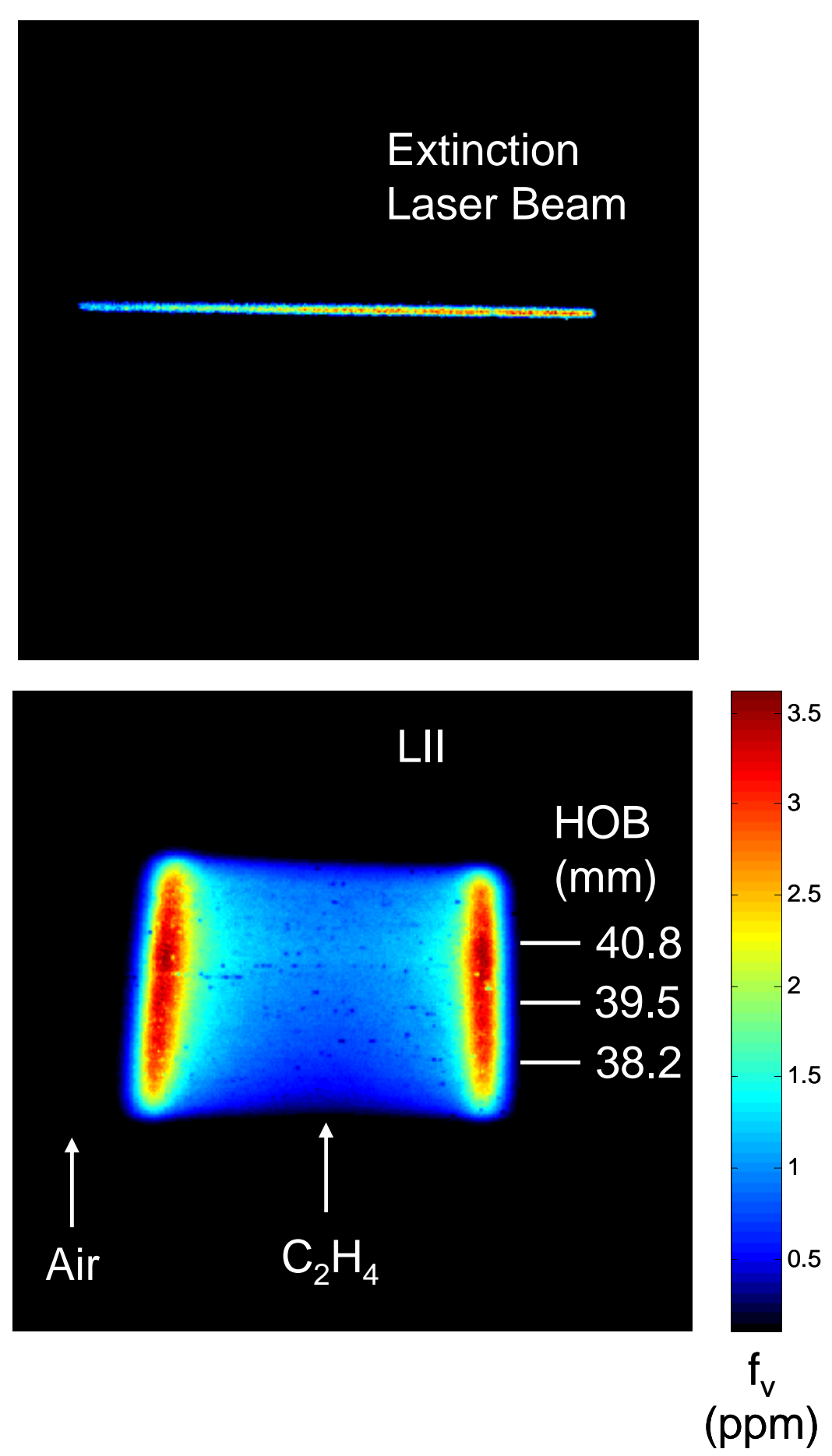

Figure 8 - Results from LII calibration flame: Rayleigh scattering indicating location of 532-nm laser beam used for calibration by light extinction (top); LII-measured sootvolume-fraction field (bottom). The scale in these images is indicated by the heightabove-burner (HOB) indicated on the LII image. 


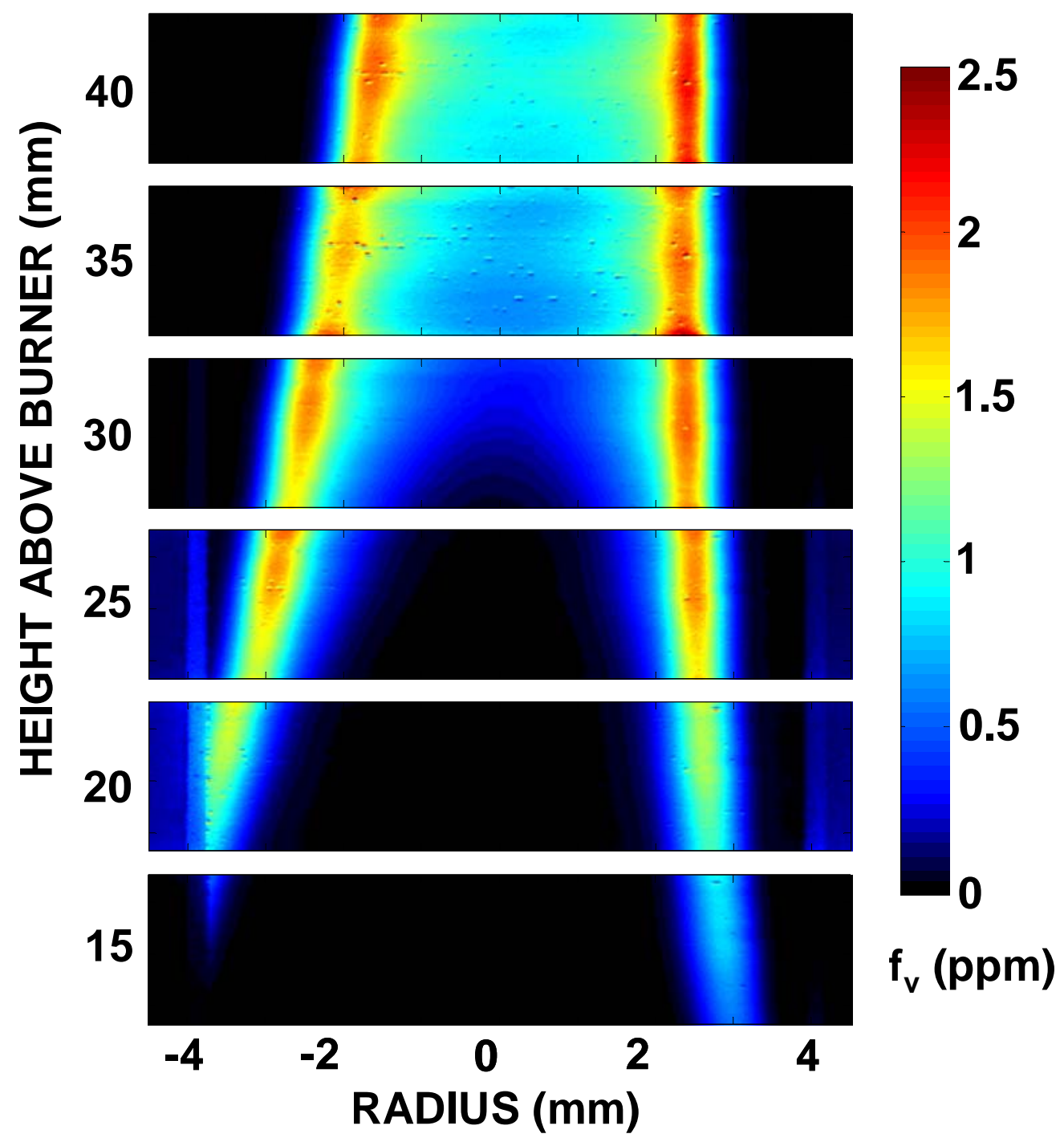

Figure 9 - Extinction-calibrated LII data from a laminar $\mathrm{C}_{2} \mathrm{H}_{4}$ /air diffusion flame. 


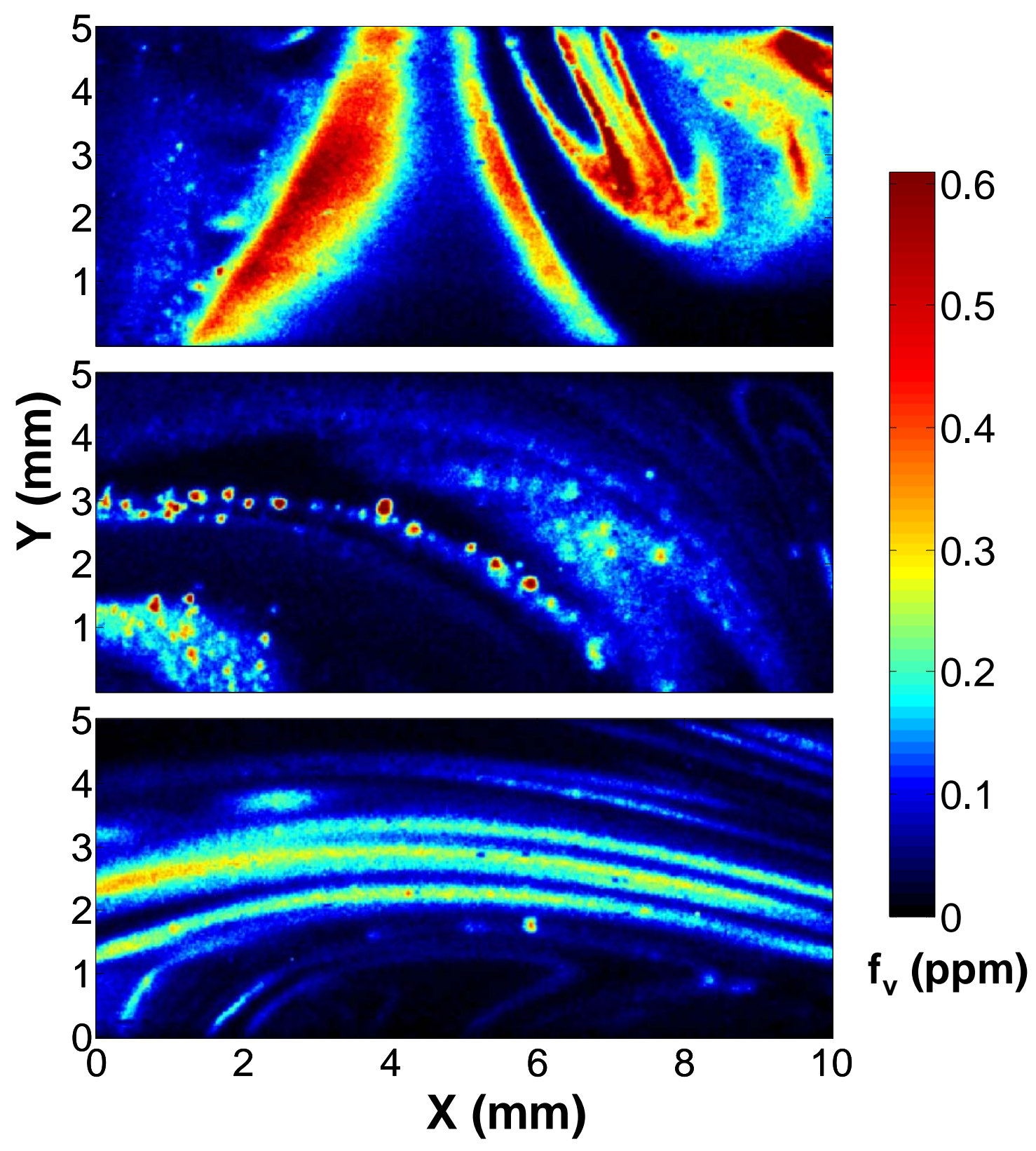

Figure 10 - LII Soot-volume fraction imaging from a 30\% toluene / 70\% methanol pool-fire experiment. 


\section{DISTRIBUTION}

$\begin{array}{llll}1 & \text { MS0384 } & \text { D. B. Dimos } & 1500 \\ 1 & \text { MS1139 } & \text { D. L. Miller } & 1530 \\ 1 & \text { MS1135 } & \text { T. K. Blanchat } & 1532 \\ 1 & \text { MS1135 } & \text { A. J. Ricks } & 1532 \\ 1 & \text { MS0821 } & \text { A. Luketa } & 1532 \\ 1 & \text { MS0828 } & \text { V. F. Nicolette } & 1532 \\ 1 & \text { MS1135 } & \text { D. A. Jernigan } & 1532 \\ 1 & \text { MS0836 } & \text { S. R. Tiezsen } & 1532 \\ 1 & \text { MS0828 } & \text { A. R. Black } & 1544 \\ 1 & \text { MS0826 } & \text { S. P. Kearney } & 1512 \\ 1 & \text { MS0836 } & \text { S. P. Domino } & 1541 \\ 1 & \text { MS0899 } & \text { Technical Library (electronic copy) } & 9536\end{array}$


I. Sandia National Laboratories 